\title{
Continuous mush disaggregation during the long-lasting Laki fissure eruption, Iceland of
}

\author{
DAVID A. NEAVE ${ }^{1,2, *}$, IRIS BUISMAN ${ }^{2}$, AND JOHN MACLENNAN ${ }^{2}$ \\ ${ }^{1}$ Leibniz Universität Hannover, Institut für Mineralogie, Callinstrasse 3, 30167 Hannover, Germany \\ ${ }^{2}$ Department of Earth Sciences, University of Cambridge, Downing Street, Cambridge, CB2 3EQ, U.K.
}

\begin{abstract}
Plagioclase textures were investigated in the products of the voluminous 1783-1784 CE Laki eruption from the Eastern Volcanic Zone (EVZ) of Iceland to establish whether mush disaggregation occurred solely at the onset of the eight-month eruption or throughout its whole duration. Phase proportions and plagioclase size distributions were determined using standard optical and manual techniques as well as automated approaches based on Quantitative Evaluation of Minerals by SCANing electron microscopy (QEMSCAN). Based on optical microscopy and the explicit combination of textural and compositional information in QEMSCAN images, plagioclase crystals were divided into two populations: small $(<0.5$ $\mathrm{mm}$ long), high-aspect ratio (length/width $>4)$ microcrysts with low-anorthite $\left(<\mathrm{An}_{80}\right)$ cores; and large ( $>0.5 \mathrm{~mm}$ long), low-aspect ratio (length/width $=2-3$ ) macrocrysts with high-anorthite $\left(\mathrm{An}_{84}-\mathrm{An}_{92}\right)$ cores. Small microcrysts grew from their carrier liquid during the final phase of pre-eruptive crystallization while large macrocrysts, which are out of geochemical equilibrium with their carrier liquids, were entrained from crystal mushes. Changes in phase proportions and plagioclase size distributions between eruptive episodes demonstrate that macrocryst entrainment efficiency varied substantially during the eruption; material erupted in later episodes contain proportionally more mush-derived material. Using stereologically corrected plagioclase size distributions, we estimate that the pre-eruptive residence times of microcrysts in the Laki carrier liquid were probably of the order of 2-20 days. Because microcryst crystallization was concurrent with macrocryst rim growth, these day-to-week residence times also indicate that macrocryst entrainment occurred on much shorter timescales than the eruption's eight-month duration. In line with constraints from independent geochronometers, macrocryst entrainment and mush disaggregation thus appears to have continued throughout the eruption. Magmas were assembled on an episode by episode basis, and the volume of eruptible magma in the plumbing system at any given time was probably closer to $1-2 \mathrm{~km}^{3}$ than the final erupted volume of $15.1 \mathrm{~km}^{3}$.

Keywords: Mush disaggregation, basalt, automated mineralogy, crystal size distributions, textures, Dynamics of Magmatic Processes
\end{abstract}

\section{INTRODUCTION}

Macrocryst entrainment from disaggregating crystal mushes is a widely recognized process in basaltic plumbing systems (Rhodes et al. 1979; Lange et al. 2013a; Neave et al. 2014). For example, primitive olivine crystals carried by evolved liquids have been interpreted as entrained macrocrysts in samples from Iceland (Thomson and Maclennan 2013), Hawai'i (Vinet and Higgins 2010), Réunion (Albarède and Tamagnan 1988), and mid-ocean ridges (Donaldson and Brown 1977). Basalt-hosted high-anorthite plagioclase macrocrysts have also been understood as disaggregated mush remnants in a range of geological settings (Hansen and Grönvold 2000; Ridley et al. 2006). Moreover, isotope and trace element disequilibria between entrained macrocrysts and their carrier liquids indicate that crystals and melts are often derived from different mantle melt distributions (Halldórsson et al. 2008; Winpenny and Maclennan 2011; Lange et al. 2013b). Mush disaggregation has also been inferred from whole-rock geo-

\footnotetext{
*E-mail: d.neave@mineralogie.uni-hannover.de

of Open access: Article available to all readers online. This is CC-BY.

Special collection papers can be found online at http://www.minsocam.org/MSA/

AmMin/special-collections.html.
}

chemical systematics, whereby elemental abundances in variably porphyritic bulk samples are controlled by element compatibilities in mush-derived components (Salaün et al. 2010; Passmore et al. 2012). Finally, macrocryst entrainment has been identified in rock textures, from the size, shape, and abundance of macrocrysts themselves (Higgins 1996; Holness et al. 2007).

Crystal size distributions (CSDs) are a powerful tool for interrogating igneous rock textures. Namely, they facilitate the investigation and quantification of crystal nucleation, growth, and mixing processes, assumptions notwithstanding (Cashman and Marsh 1988; Marsh 1988, 1998; Higgins 2000, 2006; Armienti 2008). Crystal size data are classically presented on semi-logarithmic plots of population density $(\ln [n(L)])$ vs. crystal long-axis length $(L)$, such that regressions through simple, single-crystal populations have the form:

$$
\ln [n(L)]=(-L / G \tau)+\ln \left(n^{0}\right)
$$

where $G$ is the average crystal growth rate, $\tau$ is the average crystal growth time and $n^{0}$ is the crystal nucleation density (Marsh 1988). Thus, if an average crystal growth rate is known, then an average crystal growth time can be estimated from the gradient of a CSD (Armienti et al. 1994; Higgins and Roberge 
2007; Fornaciai et al. 2015).

However, converting information from thin sections into CSDs faces two major challenges. First, to plot 2D crystal size data obtained from thin sections on explicitly 3D CSD plots it must be stereologically corrected. While Higgins (2000) presented an internally consistent tool for such corrections (CSDCorrections), 3D crystal shapes need to be uniform and well-defined to obtain reliable results, which is often not the case. Second, generating data sets for CSD calculations is time-consuming. Before crystal shape data can be determined using image analysis tools, thin section images must be digitized, which usually involves extensive manual input (Higgins 2000; Shea et al. 2010). Instruments capable of automated phase mapping (e.g., Gottlieb et al. 2000; Pirrie et al. 2004) thus represent an appealing, but as yet unevaluated, tool for the rapid acquisition of images suitable for CSD production.

In this contribution, we present phase proportion and plagioclase size data acquired from the products of the long-lasting 1783-1784 CE Laki eruption in Iceland using manual and automated Quantitative Evaluation of Minerals by SCANing electron microscopy (QEMSCAN) approaches. Using these data, we first evaluate whether automated approaches provide the same textural information as manual approaches in a reproducible and thus reliable way. We then investigate whether mush disaggregation occurred at the onset of the Laki eruption or throughout its eightmonth duration, which has important implications for understanding how large volumes of magma are mobilized in basaltic fissure eruptions and interpreting future signs of unrest.

\section{THE 1783-1784 CE LAKI ERUPTION}

The 1783-1784 CE Laki eruption, also known as the Skaftáreldar (Skaftár Fires), took place over eight months between June 8, 1783 and February 7, 1784, in the Síða highlands of southern Iceland as part of a two-year volcano-tectonic episode in the Grímsvötn volcanic system (Fig. 1). In total, $15.1 \mathrm{~km}^{3}$ of lava and tephra erupted along a $27 \mathrm{~km}$ long series of 10 en echelon fissures that opened progressively from the southwest to the northeast forming Lakagígar crater row (Thordarson and Self 1993). The opening of many fissures was preceded by elevated levels of seismicity that marked the onset of new eruptive episodes (Thordarson and Self 1993). Each of the 10 eruptive episodes is thought to have started with a brief period of explosive activity that transitioned via fire fountaining to lava effusion (Guilbaud et al. 2007). Fissures I-V opened to the southwest of Laki Mountain and discharged primarily down the Skaftá river gorge, whereas fissures VI-X opened to the northeast of Laki Mountain and discharged primarily down the Hverfisfljót river gorge. The extensive lava field produced during the eruption covers $\sim 600 \mathrm{~km}^{2}$ and extends up to $40 \mathrm{~km}$ from the source vents. Thermally efficient transport over these long distances resulted in continued evolution of the lava during emplacement (Guilbaud et al. 2007).

Although Sigmarsson et al. (1991) reported extreme homogeneity in the isotope and trace element composition of the Laki lava flow, Passmore et al. (2012) subsequently noted subtle but statistically significant variations in the composition of whole-rock samples that correlate with their macrocryst contents. Passmore et al. (2012) thus proposed that whole-rock variability in the Laki flow reflects the presence of varying amounts of a mush-derived component containing incompatible element-poor macrocrysts and incompatible element-rich interstitial melts. Using a combination of petrography and microanalysis, Neave et al. (2013) subsequently identified an assemblage of primitive macrocryst cores that were interpreted as the crystal component of this disaggregated mush.

\section{SAMPLE SELECTION AND PETROGRAPHY}

Four samples representing a range of eruptive episodes were selected from the 54 basaltic specimens described by Passmore et al. (2012) to investigate disaggregation processes throughout course of the eruption. Sampling locations are shown in Figure 1. With the exception of distally collected LAK27, which represents a crystal-rich end-member, we chose proximal samples $(<1-15$ $\mathrm{km}$ from the vent) to minimize the effects of textural evolution during transport. These samples were chosen to be representative of their episodes on the basis of their petrography and total crystal contents, which are within a few percent (absolute) of the mean values for their respective episodes (Passmore et al. 2012).

Two samples were selected from each of episodes I-V (LAK18 and LAK09) and episodes VI-X (LAK04 and LAK27). LAK18 and LAK09 were erupted southwest of Laki Mountain during episodes I and III, respectively, the highest mass flux episodes of the eruption (Thordarson and Self 1993). These rapidly quenched, porphyritic samples have low crystal contents $(<10 \%$ by area) and were collected close to their source vents ( $\sim 5$ and $<1$ km, respectively; Figs. 1 and 2c; Supplementary ${ }^{1}$ Figs. 1a and 1b). LAK04 and LAK 27 contain more crystals ( $>10 \%$ by area) and were erupted from fissures VII and VIII, respectively to the northeast of Laki Mountain (Fig. 1). LAK04 is porphyritic and was collected at a moderate distance from its source vent $(\sim 15 \mathrm{~km})$

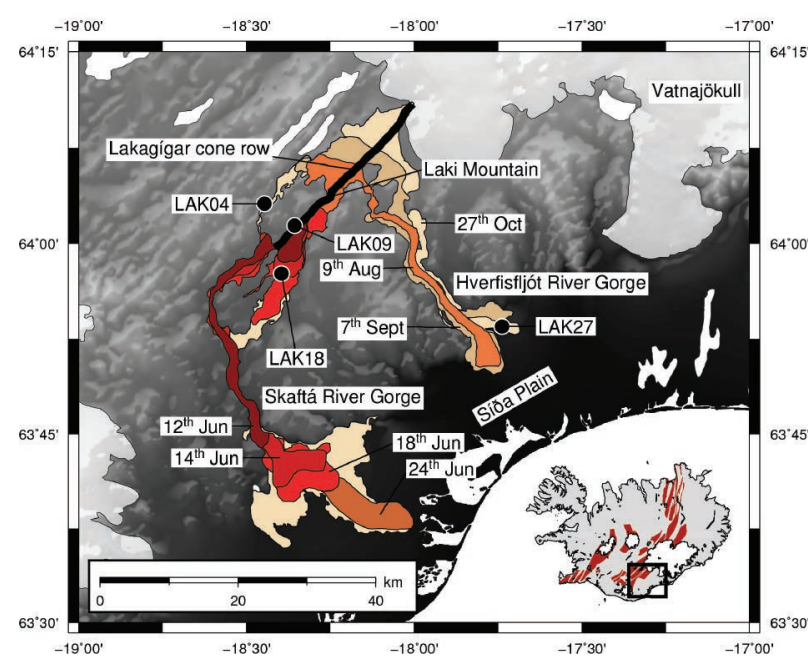

FIGURE 1. Map of the 1783-1784 CE Laki lava flow. The Lakagígar cone row, out of which the Laki lava erupted, is shown as a northeastsouthwest trending black line. The extent of the flow at different times is shown after Thordarson and Self (1993). Locations of four samples used in this study are indicated with black circles. Further details about sample locations can be found in Passmore et al. (2012). The inset map shows the location of the Laki lava within the Eastern Volcanic Zone (EVZ) of Iceland. The outlines of volcanic systems are shaded in red on the inset map. 
in the Skaftá river gorge where it cooled sufficiently rapidly to form a glassy rind (Fig. 2d; Supplementary ${ }^{1}$ Fig. 1c). In contrast, seriate LAK27 was collected from a distal flow lobe on the Síða Plain $(\sim 40 \mathrm{~km})$ and has a coarse groundmass (Figs. 2a and $2 \mathrm{~b}$; Supplementary ${ }^{1}$ Fig. 1d).

All samples contain crystals of plagioclase, clinopyroxene, and olivine (Figs. 2a and 2b). To retain consistency with previous studies, the following apparent long-axis lengths $(L)$ were used as thresholds for excluding groundmass grains: $L=0.15 \mathrm{~mm}$ for plagioclase and $L=0.20 \mathrm{~mm}$ for clinopyroxene and olivine (Passmore et al. 2012). Plagioclase crystals with $L \geq 0.15 \mathrm{~mm}$ were further divided into two populations: smaller microcrysts $(0.15$ $>L<0.5 \mathrm{~mm})$ and larger macrocrysts $(L>0.5 \mathrm{~mm})$. Within the suite of four samples investigated here, plagioclase macrocrysts reach up to $\sim 3 \mathrm{~mm}$ in length, while clinopyroxene and olivine macrocrysts reach only $\sim 1.5 \mathrm{~mm}$. In other samples from Laki,

${ }^{1}$ Deposit item AM-17-106015, Supplemental Material. Deposit items are free to all readers and found on the MSA web site, via the specific issue's Table of Contents (go to http://www.minsocam.org/MSA/AmMin/TOC/2017/Oct2017_data/ Oct2017 data.html) plagioclase and clinopyroxenes macrocrysts can reach up to $\sim 8$ $\mathrm{mm}$. Both micro- and macrocrysts have systematically more primitive compositions than groundmass grains (Neave et al. 2013): $>\mathrm{An}_{65}, \mathrm{Mg} \#_{\mathrm{Cpx}}>75$, and $>\mathrm{Fo}_{71}$.

\section{MethodS}

\section{Point-counting}

Point-counting data used in this study were collected by Passmore et al. (2012), who also provided a detailed methodological description. In summary, each slide was point-counted 3-5 times at the School of GeoSciences, University of Edinburgh, U.K., using a manually operated mechanical slide holder moved in $<0.20 \mathrm{~mm}$ increments in $x$ and $y$ directions. The following phases were counted: plagioclase, clinopyroxene, olivine, vesicles, and groundmass, which encompassed glass, mesostasis, and groundmass grains. Over 1000 points were counted in each repeat, and phase proportions were determined with the following $1 \sigma$ relative precisions according to repeat measurements: $\pm 18.4 \%$ for plagioclase, $\pm 33.6 \%$ for clinopyroxene, $\pm 45.5 \%$ for olivine, and $\pm 6.0 \%$ for the total crystal content.

\section{QEMSCAN imaging}

QEMSCAN images were produced using a Quanta 650F, field emission gun (FEG) scanning electron microscope (SEM), equipped with two Bruker XFlash 6130 energy-dispersive X-ray spectrometers (EDS) at the Department of Earth

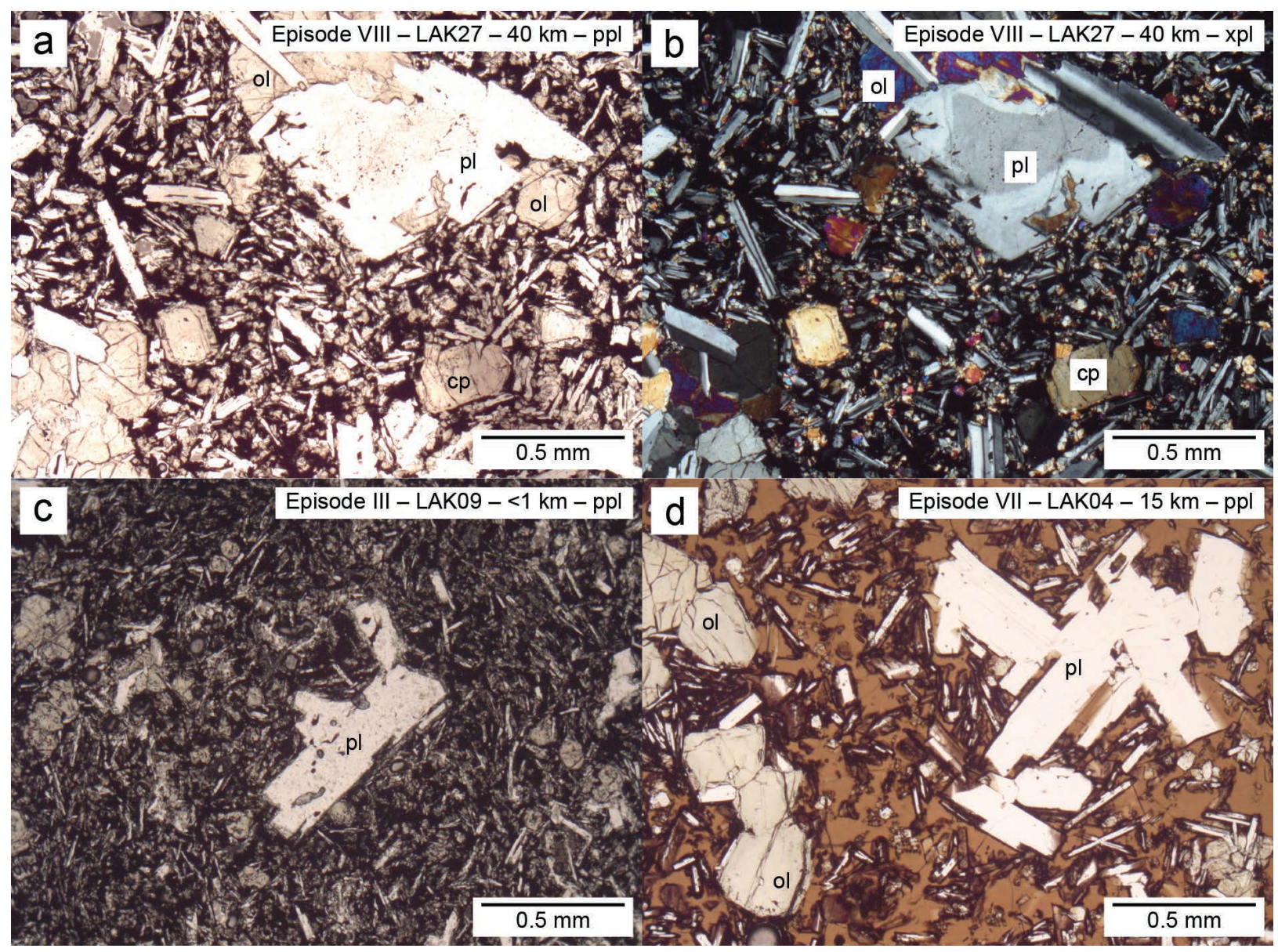

FIGURE 2. (a and b) Photomicrographs of LAK27 with plane and crossed polars, respectively, showing a typical porphyritic texture with plagioclase (Pl), clinopyroxene (Cpx), and olivine (Ol) set in a moderately fine-grained groundmass. (c) Photomicrograph with plane polars of LAK09 showing a plagioclase macrocryst set in a fine-grained groundmass. (d) Photomicrograph with plane polars of LAK04 showing a plagioclase-rich glomerocrysts set in a glassy groundmass. 


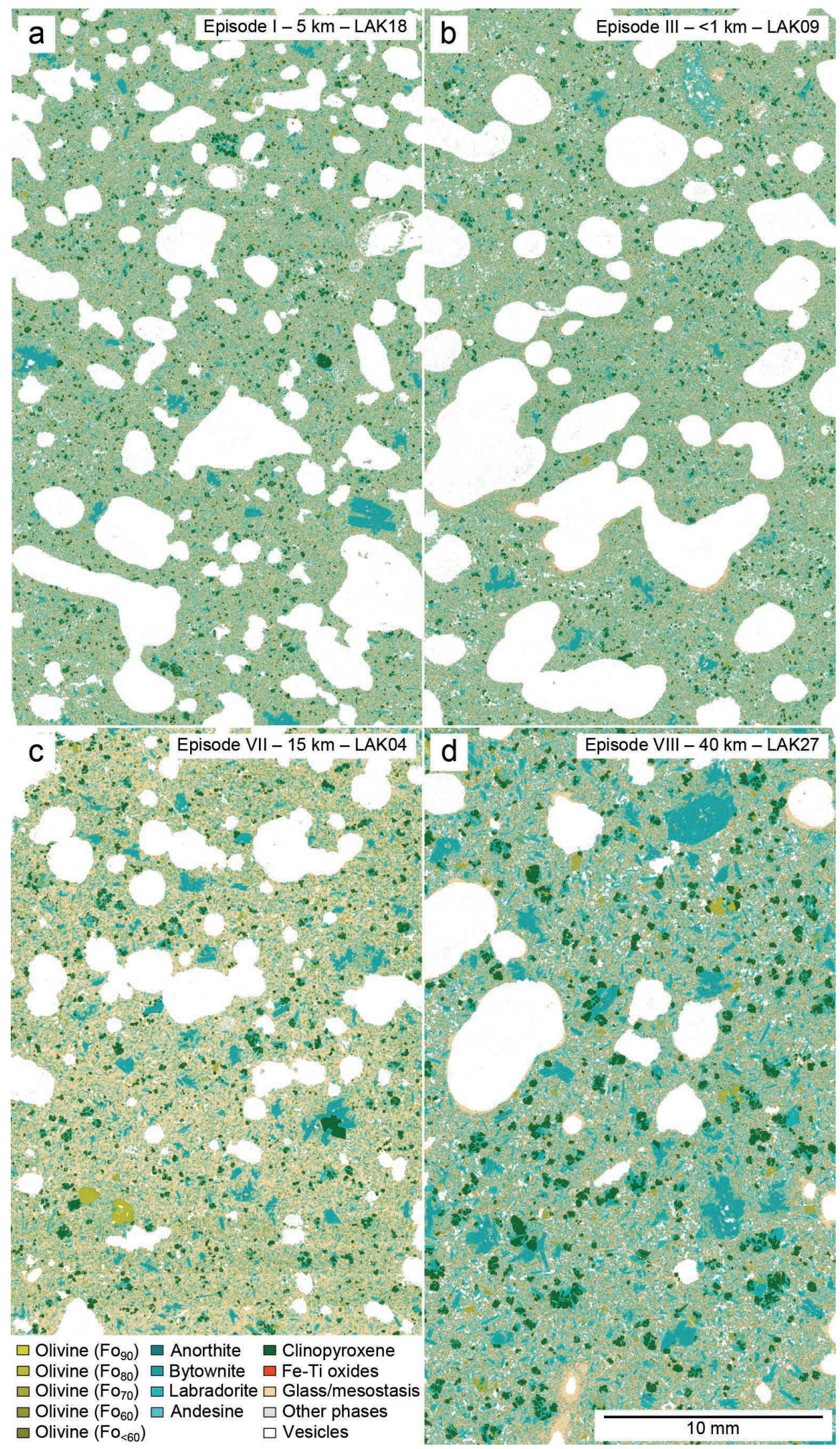

FIGURE 3. QEMSCAN images of the samples used in this study ordered by episode. Differences in crystal abundance between samples can be discerned in these phase maps. For example, the high macrocryst content of LAK27 (d) contrasts strongly with the low macrocryst content of LAK09 (b). Variability in groundmass textures is also visible: the dominantly blue coloration of seriate LAK27 (d) in contrast with the paler coloration of glassy LAK04 (c) reflects the greater degree of groundmass crystallization in the former. The presence of Fe-Ti oxides in LAK27 (d) also reflects the high degree of groundmass crystallization - the Laki lava was not Fe-Ti oxide saturated at the time of eruption (Guilbaud et al. 2007; Neave et al. 2013). 
Sciences, University of Cambridge, U.K. The fully automated system includes an energy-dispersive X-ray (EDX) spectrum acquisition and classification procedure. Analyses were performed by obtaining field scans that provided a complete characterization of sample (thin section) surfaces above a predefined backscattered electron (BSE) threshold (Gottlieb et al. 2000; Pirrie et al. 2004). BSE brightness coefficients used to apply this threshold were calibrated against quartz, gold, and copper standards. EDX spectra for each pixel were generated from $2000 \mathrm{X}$-ray counts at $25 \mathrm{kV}$ and $10 \mathrm{nA}$, and at spatial resolutions (i.e., pixel sizes) of 200, 50, and $10 \mu \mathrm{m}$. Imaging times ranged from $2 \mathrm{~min}$ for a resolution of $200 \mu \mathrm{m}$ to $8 \mathrm{~h}$ for a resolution of $10 \mu \mathrm{m}$. Spectra were then processed using species identification protocol (SIP) files that discriminated user-defined minerals on the basis of their characteristic X-ray and electron backscatter intensities computed from ideal mineral compositions normalized to the beam conditions. Images collected at spatial resolutions of 200, 50, and $10 \mu \mathrm{m}$ are henceforth referred to as Q200, Q50, and Q10 images, respectively. Q10 images are shown in Figure 3, and full images collected at all resolutions are provided in the electronic appendix ${ }^{1}$.

SIP files were produced using quantitative electron microprobe analyses from the same samples for guidance (Passmore et al. 2012; Neave et al. 2013). Plagioclase zoning was resolved using SIP files that sorted plagioclase pixels into the following compositional bins based on their relative $\mathrm{Si}, \mathrm{Al}, \mathrm{Ca}$, and $\mathrm{Na}$ contents: anorthite $\left(\sim \mathrm{An}_{90}\right)$, bytownite $\left(\sim \mathrm{An}_{80}\right)$, labradorite $\left(\sim \mathrm{An}_{60}\right)$, and andesine $\left(\sim \mathrm{An}_{40}\right)$. To improve the textural classification of plagioclase grains, images were also processed with SIP files tuned to distinguish groundmass pixels $\left(<\mathrm{An}_{65}\right)$ from micro- and macrocryst pixels $\left(>\mathrm{An}_{65}\right)$. Comparing QEMSCAN images with published electron microprobe data suggests that plagioclase anorthite contents were generally determined with a precision better than $20 \mathrm{~mol} \%$ under the conditions used; QEMSCAN images nevertheless contain some noise reflecting the incorrect binning of some pixels. Olivine zoning was resolved in a similar manner by using relative $\mathrm{Mg}$ and $\mathrm{Fe}$ contents.

\section{Determining plagioclase sizes}

Plagioclase sizes were obtained from two suites of digitized images. The first suite of images was obtained by manually tracing plagioclase crystals on highresolution (4000 dpi) thin sections scans in Inkscape, which took approximately $20 \mathrm{~h}$ per thin section. For consistency with point-counting data, we excluded groundmass grains with $L<0.15 \mathrm{~mm}$. Vesicles were also traced to calculate vesicle-free population densities. Crystal and vesicle size data then were extracted from these digitized images using the analyze particles tool in ImageJ (Abràmoff et al. 2004).

The second suite of images was generated from QEMSCAN analyses using FEI's iExplorer software package. Plagioclase sizes were estimated from these images in two ways. First, plagioclase sizes were determined using the granulator tool within iExplorer that segments and measures discrete particles of user-specified phases. Second, plagioclase sizes were determined from a set of granulated QEMSCAN images that were manually rectified to separate glomerocrysts into individual macrocrysts (e.g., Shea et al. 2010). Rectification was necessary because QEMSCAN analyses do not discriminate between touching crystals of the same composition; QEMSCAN images are phase maps, not grain maps. Rectified images were then measured using ImageJ in the same manner as the manually traced images.

Plagioclase areas determined using ImageJ and iExplorer were calculated by summing the total number of pixels within each particle in images to which thresholds had been applied. Uncertainties in particle areas therefore reflect a trade-off between image resolution and particle size. Given that each erroneous pixel in an 80-pixel particle (10-pixel equivalent diameter) represents a relative error of $\sim 1 \%$, manually traced images were processed at a resolution that ensured all plagioclase crystals with $L>0.15 \mathrm{~mm}$ were $>80$ pixels in area. Similarly, QEMSCAN images were collected at a resolution of $10 \mu \mathrm{m}$ to ensure that plagioclase crystals with $L>0.15 \mathrm{~mm}$ and realistic length/width aspect ratios of three cover $\geq 75$ pixels. Although QEMSCAN images could have been collected at higher resolutions, much longer acquisition times would have been required; imaging at a resolution of $2 \mu \mathrm{m}$ would have taken $\sim 25$ times longer than imaging at a resolution of $10 \mu \mathrm{m}$.

While particle areas are reliably determined by both ImageJ and iExplorer, fitted ellipse dimensions from the ImageJ analyze particle tool must be corrected to give true particle dimensions; the shape of a best-fitting ellipse is not the same as the shape of the particle to which it is fitted. We therefore developed two simple calibrations for determining true particles shapes by measuring synthetic images of particles of known dimensions (Supplementary ${ }^{1}$ Fig. 2). Synthetic particle lengths were consistently overestimated using the analyze particles tool and thus corrected using the relationship:

$L_{\text {true }}=0.890 \times L_{\text {measured }}-0.092$.
Synthetic particle aspect ratios $(A R)$, which incorporate uncertainties in lengths and widths, were also corrected as follows:

$$
A R_{\text {true }}=1.150 \times A R_{\text {measured }}-0.195 \text {. }
$$

\section{Crystal size distribution calculations}

The classic presentation of CSD data on semi-logarithmic plots of $\ln [n(L)]$ vs. $L$ requires stereological conversion of $2 \mathrm{D}$ crystal size data. In order for such conversions to be accurate, crystals must define a single population of known and constant morphology (Higgins 2000). Although it is possible to make reasonable assumptions about crystal morphology within a single population based on crystal length and width data (Morgan and Jerram 2006), such assumptions cannot be applied across the multiple plagioclase populations present in the Laki lava (Guilbaud et al. 2007; Neave et al. 2013).

To identify different macrocryst populations while avoiding the pitfalls of stereological conversion, CSDs determined from all images were evaluated first on semi-logarithmic plots of number area density $\left(N_{A}\right)$ normalized by bin width $(b w)$ vs. the square root of crystal area $\left(A^{0.5}\right)$. By plotting crystal size as $A^{0.5}$ rather than $L$, the effect of crystal morphology on stereologically uncorrected CSDs can be reduced (Neave et al. 2014). Furthermore, the following two binning strategies were used to ensure that our interpretations were not affected by how we chose to present the data: linear binning with a spacing of $0.05 \mathrm{~mm}$ (Armienti 2008), and geometric binning where each successive bin was a factor of $10^{0.1}$ larger than the last (Sahagian and Proussevitch 1998).

Having identified coherent plagioclase populations using stereologically uncorrected CSDs, we then calculated classic $\operatorname{CSDs}(\ln [n(L)]$ vs. $L)$ from traced thin section images. Best-fitting crystal shapes were first estimated from corrected plagioclase lengths and widths using CSDslice (Morgan and Jerram 2006). These best-fitting shapes were then used with corrected plagioclase lengths to calculate geometrically binned CSDs using CSDCorrections (Higgins 2000). Owing to the small number of macrocrysts present ( $<75$ with $L>0.5 \mathrm{~mm}$ after conversion), stereological conversions were only applied to statistically robust microcryst populations.

\section{Phase proportions}

\section{RESUlTS}

Total crystal contents and phase proportions determined by manual point-counting and QEMSCAN imaging are shown in Figure 4. Total crystal contents estimated by manual pointcounting vary between 8.4 and $28.4 \%$ by area, and correlate loosely with surface transport distance and position in the eruption chronology. In contrast, total crystal contents estimated from QEMSCAN imaging vary between 32.9 and $64.4 \%$ by area. Phase proportion estimates also differ significantly between manual and automated techniques, with QEMSCAN data sets returning more plagioclase than manually obtained data sets (Fig. 4). Reasons for these discrepancies are discussed below. Total crystal contents and phase proportions estimated from QEMSCAN analyses performed at different resolutions (10-200 $\mu \mathrm{m})$ are indistinguishable (Fig. 4).

Independent estimates of plagioclase contents from traced thin section images are compared with estimates from manual point-counting and QEMSCAN analyses in Figure 5. Plagioclase proportions determined by manual point-counting and image tracing generally agree; with the exception of plagioclase proportions from macrocryst-poor LAK09, estimates from image tracing are within the $2 \sigma$ uncertainty of estimates from manual point-counting. However, plagioclase proportions determined by QEMSCAN imaging exceed those from manual methods by factors of 2.2-12.0. For example, while manual point-counting and image tracing return plagioclase content estimates of 6.5 and $6.4 \%$ for LAK04, respectively, the Q10 image contains $22.8 \%$ plagioclase by area. Granulating this Q10 image and discarding plagioclase particles with $L<0.15 \mathrm{~mm}$, which would exclude all groundmass grains if segmentation were perfectly efficient, leads 
a $\quad$ Episode I - $5 \mathrm{~km}-$ LAK18

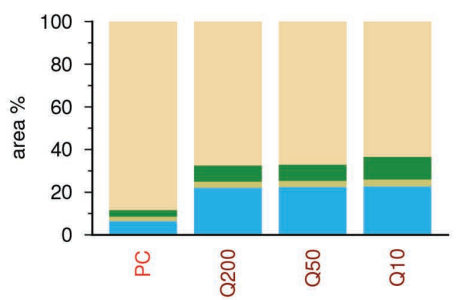

b Episode III $-<1 \mathrm{~km}-$ LAKO9

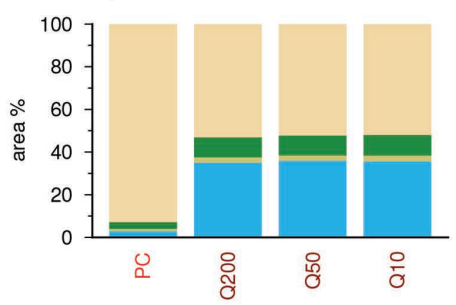

C Episode VII - $15 \mathrm{~km}$ - LAK04

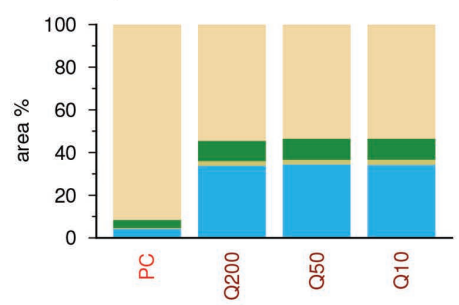

d Episode VIII - $40 \mathrm{~km}-$ LAK27

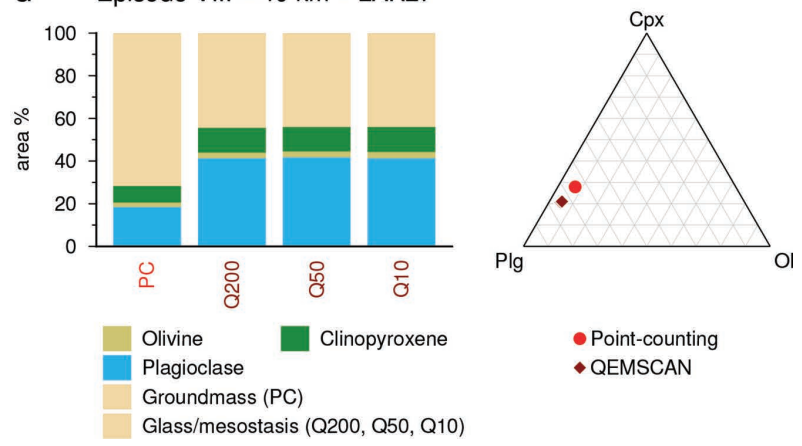

FIGURE 4. Bar charts and ternary diagrams illustrating the variability in sample crystal contents and phase proportions estimated using different methods: PC, point-counting data from Passmore et al. (2012); Q200, QEMSCAN imaging with a spatial resolution of $200 \mu \mathrm{m}$; Q50 $=$ QEMSCAN imaging with a spatial resolution of $50 \mu \mathrm{m}$; and Q10 = QEMSCAN imaging with a spatial resolution of $10 \mu \mathrm{m}$. Glass, mesostasis, and groundmass grains are counted as groundmass in point-counting data sets, but only glass and mesostasis are counted as groundmass in QEMSCAN data sets. Macrocrysts, microcrysts, and groundmass grains are thus merged in QEMSCAN data sets while they are separated in point-counting data sets.

to a reduction in estimated plagioclase proportions to $18.0 \%$ by area (Q10G; Fig. 5). Manual rectification of granulated images to break apart glomerocrysts before discarding particles with $L$ $<0.15 \mathrm{~mm}$ reduces estimated plagioclase proportions to $14.1 \%$ by area (Q10R; Fig. 5). However, even after manual rectification, plagioclase contents estimated by automated methods still exceed estimates from manual techniques in all samples by factors of 1.6-4.3.

Processing QEMSCAN images with SIP files tuned to distinguish between micro- and macrocryst, and groundmass plagioclase compositions ( $>\mathrm{An}_{65}$ and $<\mathrm{An}_{65}$, respectively) leads to significant improvements in plagioclase phase proportion estimates (Q10S; Figs. 5 and 6). After tuning SIP files, estimated plagioclase contents are $8.1-14.0 \%$ by area, factors of $0.8-2.7$ different from manual estimates. However, several falsely identified high-anorthite pixels still occur within sample groundmasses, which is consistent with the tendency to overestimate plagioclase contents (Fig. 6).

\section{Plagioclase size-morphology relationships}

Plagioclase aspect ratios (length/width) determined from traced images are plotted against crystal size $\left(A^{0.5}\right)$ in Figure 7. Aspect ratios are not shown for QEMSCAN data sets because segmentation was insufficiently reliable. Plagioclase morphology varies systematically as a function of grain size: macrocrysts ( $A^{0.5}>0.2 \mathrm{~mm}$, which is equivalent to $L>0.5 \mathrm{~mm}$ ) are equant and have mean aspect ratios of $2-3$, whereas microcrysts $\left(A^{0.5}\right.$ $<0.2 \mathrm{~mm}$, which is equivalent to $L<0.5 \mathrm{~mm}$ ) are elongate and usually have aspect ratios $>4$. Given that the shape of plagioclase grains reflects their crystallization histories (Lofgren 1974; Higgins 1996; Holness 2014), these size-morphology relationships confirm the presence of multiple plagioclase populations (cf. Neave et al. 2013).

\section{a}

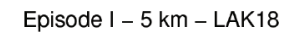

b Episode III - <1 km - LAK09
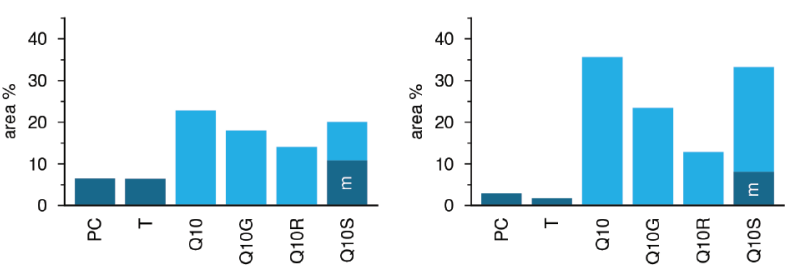

C

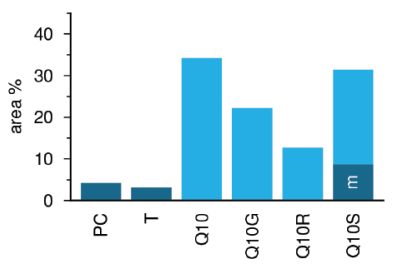

d Episode VIII - $40 \mathrm{~km}-$ LAK27

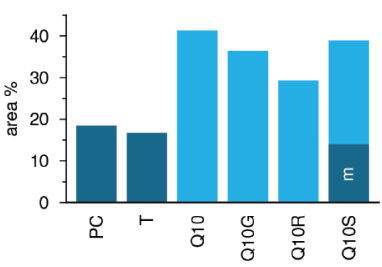

FIGURE 5. Bar charts comparing estimates of sample plagioclase contents obtained using different methods. From left to right within each plot: $\mathrm{PC}=$ plagioclase crystals with $L>0.15 \mathrm{~mm}$ from point-counting data (Passmore et al. 2012); $\mathrm{T}=$ plagioclase crystals with $\mathrm{L}>0.15 \mathrm{~mm}$ traced from high-resolution thin section scans; Q10 = sum of all plagioclase particles in QEMSCAN images with a spatial resolution of $10 \mu \mathrm{m}$; Q10G $=$ sum of plagioclase particles with $L>0.15 \mathrm{~mm}$ in granulated QEMSCAN images with a spatial resolution of $10 \mu \mathrm{m}$; Q10R $=$ sum of plagioclase particles with $L>0.15 \mathrm{~mm}$ from rectified QEMSCAN images with a spatial resolution of $10 \mu \mathrm{m}$ resolution; and Q10S = relative proportions of plagioclase micro- and macrocrysts ( $>\mathrm{An}_{65}$; dark blue; marked " $\mathrm{m}$ ") and groundmass grains $\left(<\mathrm{An}_{65}\right.$; light blue) from $\mathrm{QEMSCAN}$ images processed using tuned SIP files. 


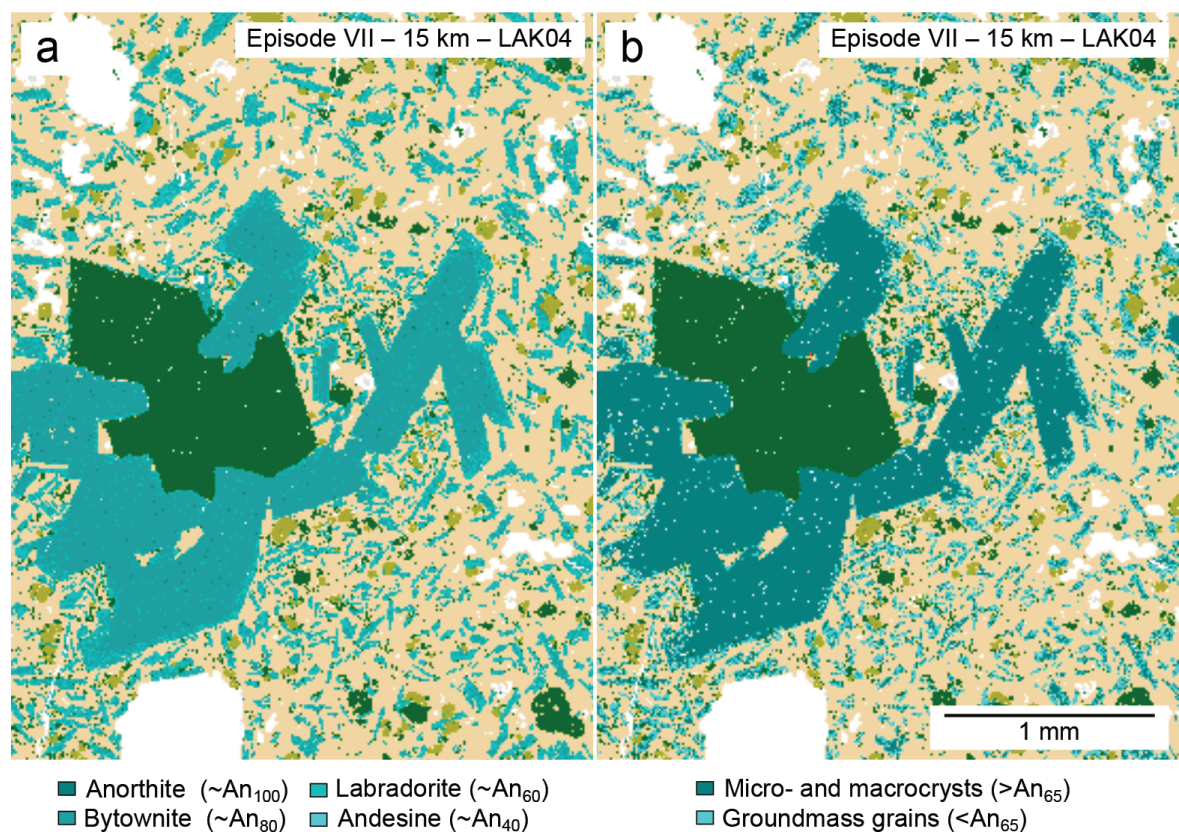

FIGURE 6. Comparison of plagioclase pixel classifications in QEMSCAN images using: (a) four compositional groups ranging from anorthite to andesine; and (b) two compositional groups tuned to distinguish between microcryst and macrocrysts compositions $\left(>\mathrm{An}_{65}\right.$ ), and groundmass compositions $\left(<\mathrm{An}_{65}\right)$. Many pixels in both large and small plagioclase grains are classified as labradorite in a, making it difficult to distinguish between microcrysts and the groundmass. In $\mathbf{b}$, low-anorthite $\left(<\mathrm{An}_{65}\right)$ pixels are mainly restricted to macrocryst rims and groundmass grains. However, several high-anorthite $\left(>\mathrm{An}_{65}\right)$ pixels are still identified in even the smallest grains; higher count spectra would be required to improve classification accuracy further.

\section{Plagioclase size-composition relationships}

QEMSCAN imaging combines textural and compositional information within single data sets, a notable advantage over other textural techniques. To characterize plagioclase size-composition relationships, we plotted the mean anorthite content of plagioclase particles as a function of their size (Fig. 8). Anorthite contents were estimated by calibrating granulated and rectified QEMSCAN images against the compositions used to generate SIP file entries. However, given the small number of plagioclase species that can be distinguished using the low count spectra necessary for the timely production of QEMSCAN images, these calibrations are only semi-quantitative. Robust size-composition relationships can nonetheless be identified in all samples: large particles are dominated by high-anorthite contents whereas small particles have variable but, on average, lower anorthite contents.

Porphyritic samples (LAK18, LAK09, and LAK04) have similar size-composition systematics (Figs. 8a-8c). The largest macrocrysts $\left(A^{0.5}>0.4 \mathrm{~mm}\right)$ have highly anorthitic mean compositions $\left(\mathrm{An}_{84}-\mathrm{An}_{92}\right)$ that lie within the range of published highanorthite core compositions for Laki (Guilbaud et al. 2007; Neave et al. 2013). The large scatter in apparent microcryst compositions $\left(A^{0.5}<0.2 \mathrm{~mm}\right)$ notwithstanding, the mean anorthite contents of these grains are slightly higher than those reported previously for microcrysts and macrocryst rims $\left(\mathrm{An}_{67}-\mathrm{An}_{70}\right.$ vs. $<\mathrm{An}_{65}$; Guilbaud et al. 2007; Neave et al. 2013). This offset probably relates to the frequent false identification of primitive bytownite pixels $\left(\sim \mathrm{An}_{80}\right)$ in zones of labradoritic composition $\left(\sim \mathrm{An}_{60} ; \mathrm{Fig}\right.$. 6a). Seriate LAK27 shows a similar trend in plagioclase size-composition space to the other samples that is offset to systematically lower anorthite contents; all plagioclase particles contain a greater proportion of labradorite pixels in LAK27 (Fig. 8d), reflecting the extensive groundmass crystallization experienced by this sample.

\section{Plagioclase size distributions without stereological corrections}

Plagioclase size distributions calculated from traced images are plotted in Figure 9 using diamond symbols. Most plagioclase crystals lie within the size range $A^{0.5}=0.1-1 \mathrm{~mm}$, though a few larger grains are present in LAK27. All CSDs are kinked, with microcryst and macrocryst populations defining distinct arrays. The kink separating these populations occurs at $A^{0.5} \sim 0.3 \mathrm{~mm}$ in most samples but is shifted to $A^{0.5} \sim 0.4 \mathrm{~mm}$ in LAK27 because of this sample's higher crystallinity (Fig. 5; Cashman and Marsh 1988; Higgins 1996). Note, however, that mean microcryst sizes are significantly smaller than the sizes indicated by kink points; kink positions are not equivalent to the size thresholds used to distinguish between plagioclase populations $\left(L=0.5 \mathrm{~mm} ; A^{0.5}=\right.$ $0.2 \mathrm{~mm}$ ). Grains smaller than $A^{0.5} \sim 0.1 \mathrm{~mm}$ are below the $L=0.15$ $\mathrm{mm}$ threshold applied during tracing, resulting in an artificial drop in population density at the smallest grain sizes. CSDs calculated from linearly and geometrically binned data show similar trends for all samples; fits to plagioclase populations are independent of binning style when data are sufficiently dense. Kinks between microcryst and macrocryst populations also occur at similar $A^{0.5}$ values in the differently binned data sets. For geometrically binned data, intercepts of fits to microcryst populations (i.e., values of $N_{A}$ / $b w$ at $\left.A^{0.5}=0 \mathrm{~mm}\right)$, which are proxies for nucleation densities $\left(n^{0}\right)$, 

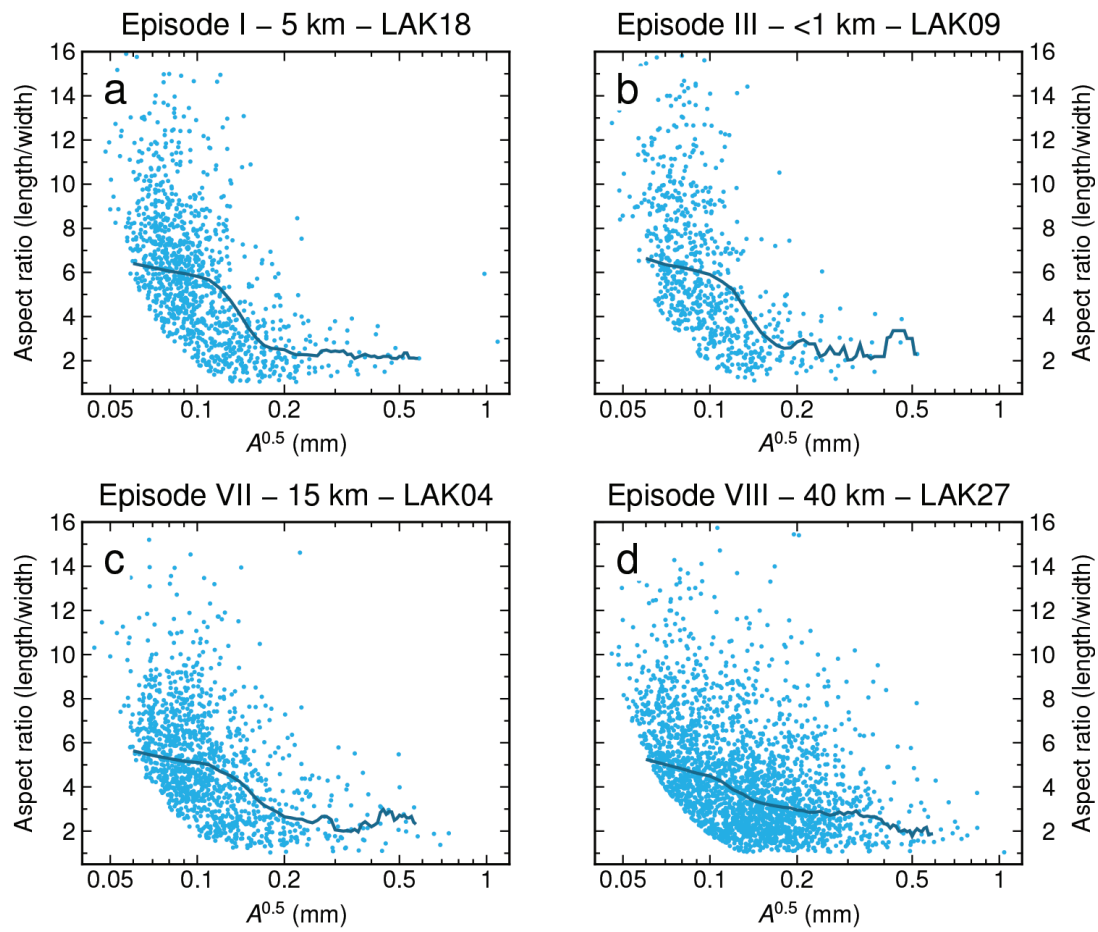

FIGURE 7. Plots showing how aspect ratio (length/width) varies as a function of crystal size $\left(A^{0.5}\right)$ for plagioclase grains segmented from traced thin section images (T). Dark blue lines show running mean aspect ratios calculated by passing Gaussian filters with 0.1 mm bandwidths across each data set.
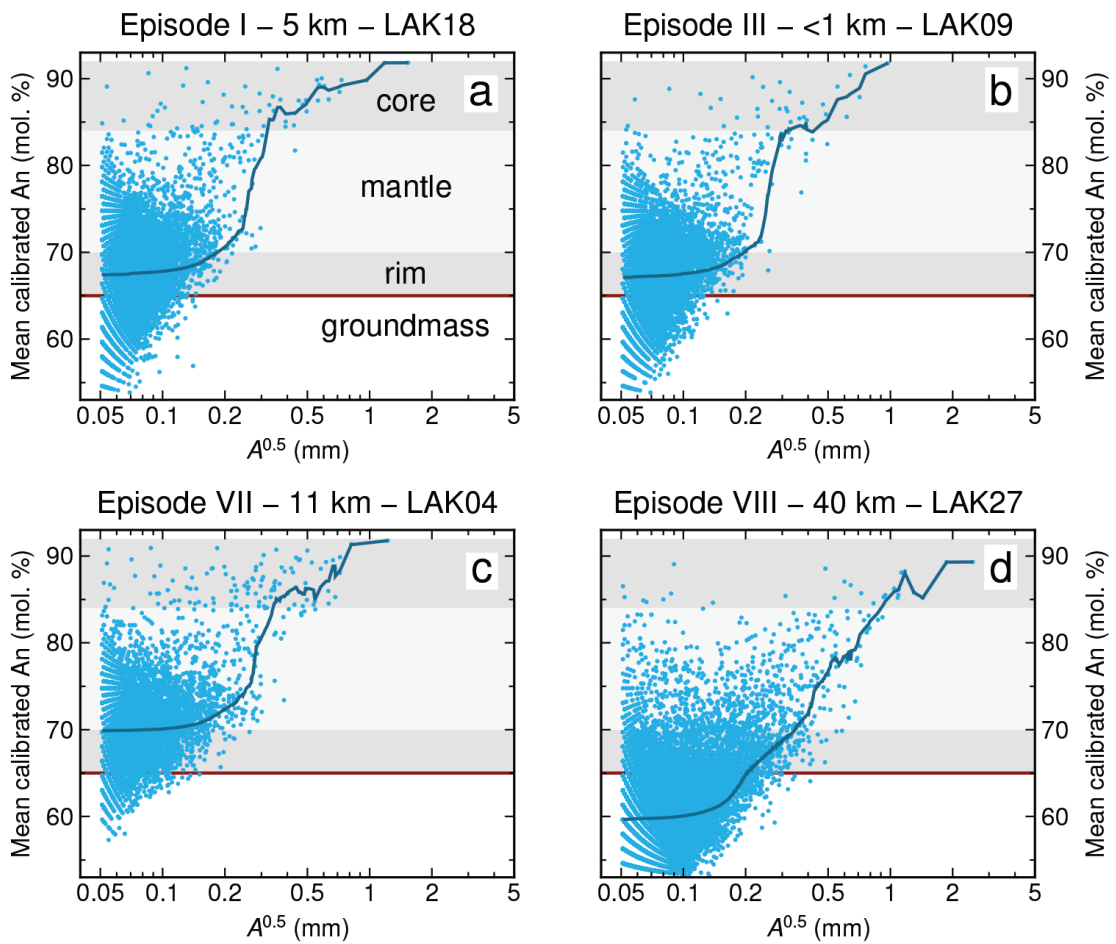

FIGURE 8. Plots showing how the mean anorthite content of plagioclase particles segmented from rectified QEMSCAN images (Q10R) varies as a function of plagioclase size $\left(A^{0.5}\right)$. Dark blue lines show running mean anorthite contents calculated by passing Gaussian filters with $0.1 \mathrm{~mm}$ bandwidths across each data set. Gray fields show the anorthite range of compositional zones in Laki plagioclase grains defined by Neave et al. (2013). Red horizontal lines show the compositional divide between microcryst and groundmass compositions. 
Geometric binning

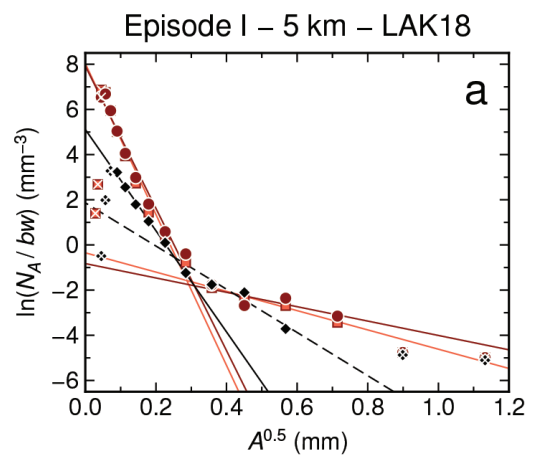

Episode III $-<1 \mathrm{~km}-$ LAK09

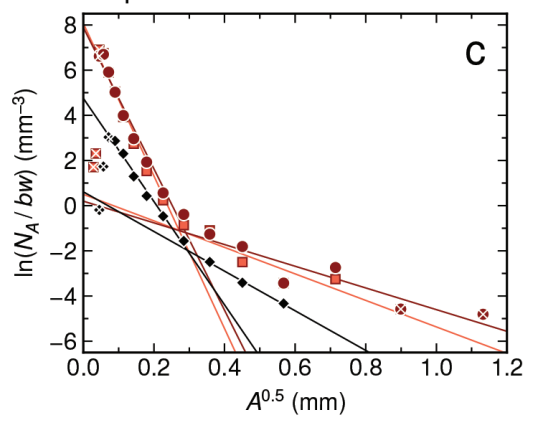

Episode VII - 15 km - LAK04

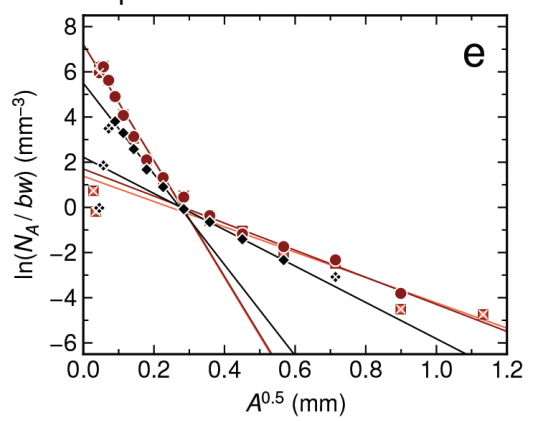

Episode VIII - 40 km - LAK27

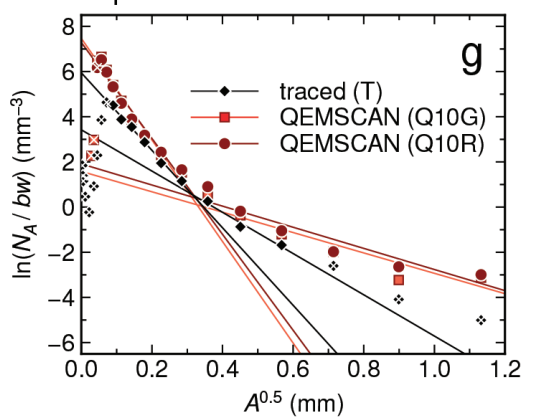

Linear binning

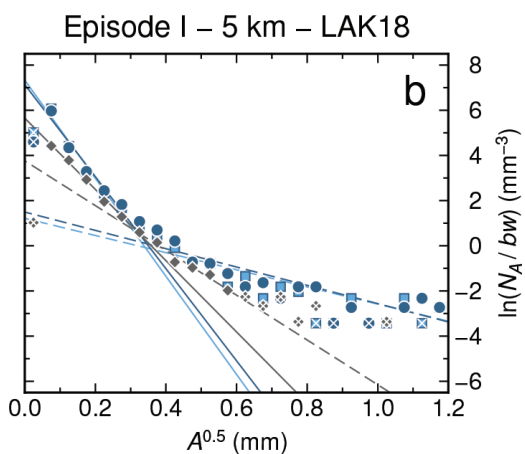

Episode III - $<1$ km - LAK09

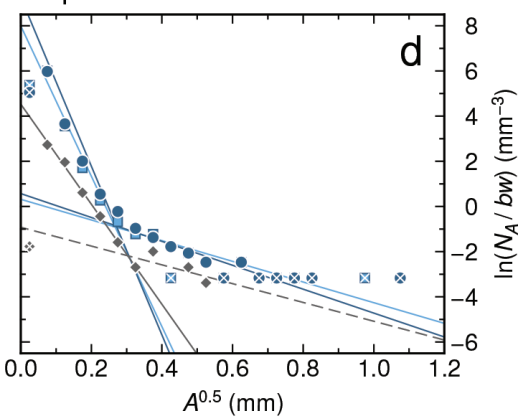

Episode VII - 15 km - LAK04

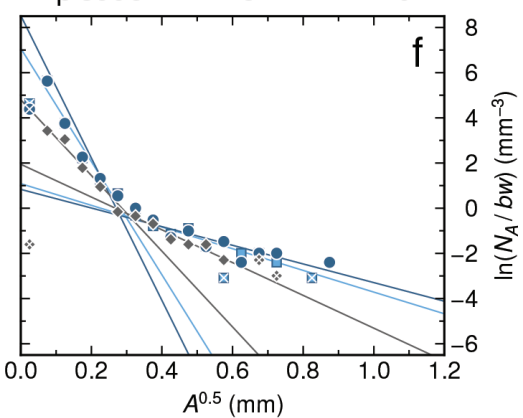

Episode VIII - 40 km - LAK27

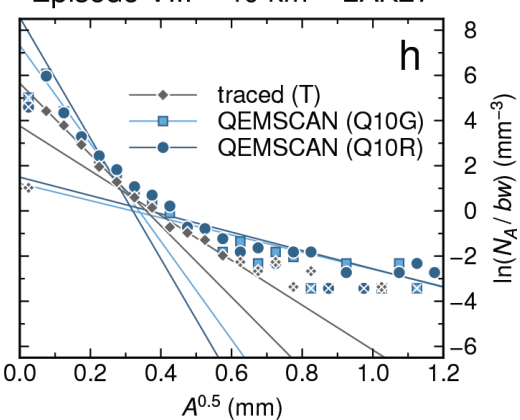

FIGURE 9. Plagioclase size distributions showing crystal population density per unit area normalized by bin width in $\mathrm{mm}^{-3}\left[\ln \left(N_{A} / b w\right)\right]$ plotted against the square root of plagioclase area in $\mathrm{mm}\left(A^{0.5}\right)$. Data processed using a geometric binning strategy are shown in the left-hand column (a, c, e, and $\mathbf{g}$ ) (Sahagian and Proussevitch 1998), and data processed using a linear binning strategy are shown in the righthand column (b, d, f, and h) (Armienti 2008). Distributions from traced thin section images (T) unrectified but granulated QEMSCAN images (Q10G) and rectified QEMSCAN images (Q10R) are plotted using diamonds, squares and circles, respectively. Distinct plagioclase populations can be identified in all distributions. Linear regressions through each population with $r^{2}>0.7$ are shown as solid lines, whereas those with $r^{2}<0.7$ are shown as dashed lines. Data shown with white crosses are excluded from regressions either because they lie below the spatial resolution of measurements or because they represent under-sampled bins containing only one crystal (Armienti 2008). lie between 148 and $403 \mathrm{~mm}^{-3}$. Intercepts of fits to macrocryst populations lie between 2.7 and $12.2 \mathrm{~mm}^{-3}$.

Plagioclase size distributions calculated from unrectified and rectified Q10 images are plotted in Figure 9 using square and circular symbols, respectively. QEMSCAN-derived CSDs show the same primary features as CSDs calculated from traced thin section scans: populations of small and large plagioclase crystals separated by breaks in CSD slopes at $A^{0.5} \sim 0.3 \mathrm{~mm}$. However, there are two important differences between CSDs obtained from tracing and from QEMSCAN images. First, plagioclase number densities estimated from Q10 images are substantially higher than those from traced images. For example, intercepts of fits to microcrysts 
in both unrectified and rectified Q10 CSDs lie between 1097 and $2981 \mathrm{~mm}^{-3}$ in comparison with values of between 148 and 403 $\mathrm{mm}^{-3}$ from CSDs from traced images. And, second, CSDs from QEMSCAN images are more smoothly concave than traced CSDs. Reasons for these differences are discussed below.

\section{Plagioclase size distributions with stereological corrections}

Plagioclase morphology varies as function of plagioclase size in the Laki lava (Fig. 7). Therefore, a single stereological correction cannot not be applied across the full range of plagioclase sizes present in each sample: currently available stereological correction schemes assume a uniform shape across all crystal sizes (Higgins 2000). Classic CSDs for estimating timescales of magmatic processes were thus calculated using plagioclase morphologies estimated from microcrysts $(L<0.5 \mathrm{~mm})$. Separate conversions for macrocryst populations could not be performed because our samples do not contain sufficient numbers of macrocrysts to reconstruct $3 \mathrm{D}$ grain shapes robustly $(>75$; Morgan and Jerram 2006). Furthermore, macrocrysts are more primitive than microcrysts (Fig. 8) and record events that occurred before the final assembly and eruption of the Laki magma; chemical and structural complexity within large plagioclase macrocrysts from the Laki lava has been interpreted in terms of magma mixing and crystal mush entrainment (Guilbaud et al. 2007; Passmore et al. 2012; Neave et al. 2013). It is thus unclear what geological meaning could be extracted from the apparent crystallization timescales of large crystals that may have been resident in the plumbing system for thousands of years (e.g., Cooper et al. 2016).

Stereologically corrected CSDs are shown in Figure 10. Linear fits through microcryst populations in the porphyritic samples (LAK18, LAK09, and LAK04) have similar intercepts $\left(n^{0}=394-460 \mathrm{~mm}^{-4}\right)$, whereas the intercept for seriate LAK27 is slightly higher $\left(n^{0}=667 \mathrm{~mm}^{-4}\right)$. Gradients $(-1 / G \tau)$ of fits through data from episodes I and III (LAK18 and LAK09) are somewhat more negative than the gradients of fits through data from episodes VII and VIII (LAK04 and LAK27): $-1 / G \tau=-12.2$ to $-11.1 \mathrm{~mm}^{-1}$ vs. -9.5 to $-8.4 \mathrm{~mm}^{-1}$, respectively.

\section{DISCUSSION}

\section{Manual and automated methods of textural quantification}

Total crystal contents and phase proportions determined by manual and automated point-counting techniques differ significantly (Figs. 4 and 5). We suggest two main reasons for this: first, microcrysts were not discriminated efficiently from groundmass grains by automated point-counting; and second, automated processing methods are poor at segmenting glomerocrysts.

A minimum size threshold of $L=0.15 \mathrm{~mm}$ was imposed when distinguishing microcrysts from groundmass grains during manual point-counting (Passmore et al. 2012). However, groundmass grains were not distinguished from microcrysts during the initial processing of QEMSCAN images; all pixels identified as plagioclase, clinopyroxene, or olivine contributed toward estimates of total crystal content. While points identified manually as groundmass encompassed glass, mesostasis, and fine-grained groundmass crystals, only glass and mesostasis were categorized as groundmass during QEMSCAN imaging.

Separating micro- and macrocryst pixels from groundmass pix- els based on their composition was the most successful method for bringing manual and automated data sets into alignment: tuning SIP files resulted in plagioclase contents $0.8-2.7$ times the magnitude of contents estimated using manual techniques. Numerous misclassified pixels (e.g., low-anorthite pixels in macrocryst cores) nonetheless remained, indicating that higher count spectra $(>5000$ counts) would be required to discriminate between compositionally different plagioclase populations robustly. Alternatively, QEMSCAN phase maps could be converted into grain maps by integrating crystal orientation information from electron backscattered diffraction (EBSD) analyses (e.g., Prior et al. 1999; Cordier et al. 2014).

Population densities determined from traced and QEMSCAN images are compared in Figure 11. Plagioclase population densities calculated from QEMSCAN images are almost always higher than those calculated from traced images regardless of the binning style or degree of rectification (Figs. 11a and 11b). The difference in population density between manual and automated methods also varies as a function of plagioclase size (Figs. 11c and 11d): QEMSCAN population densities $\left[\ln \left(N_{A} / b w\right)\right]$ are up to three $\log$ units higher at small grain sizes $\left(A^{0.5} \sim 0.1 \mathrm{~mm}\right)$, but only half a log unit higher at larger grain sizes $\left(A^{0.5}>0.2 \mathrm{~mm}\right)$.

Although CSDs from manually traced images are susceptible to some uncertainties (e.g., tracing precision and imaging resolution), the linearity of microcryst CSDs indicates that no size-dependent sampling biases are present over the $A^{0.5}=0.1-0.3 \mathrm{~mm}$ interval. In contrast, the inefficient segmentation of small plagioclase particles in QEMSCAN images is especially notable at the smallest

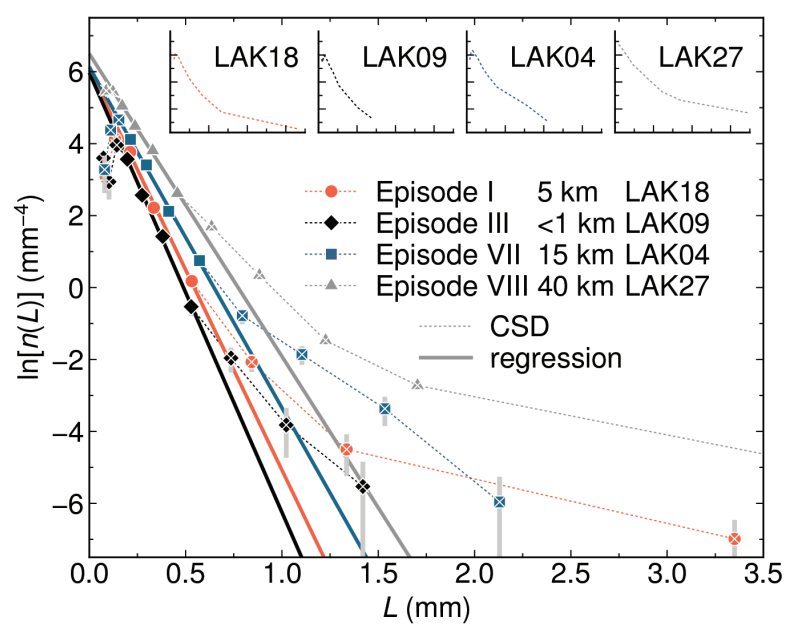

FIGURE 10. Classic CSDs showing crystal population density in $\mathrm{mm}^{-4}$ $(\ln [n(L)])$ plotted against geometrically binned crystal length in $\mathrm{mm}(L)$. CSDs were calculated using CSDCorrections (Higgins 2000) with best fitting microcryst shapes determined using CSDslice (Morgan and Jerram 2006). Vertical gray bars indicate uncertainties associated with stereological conversions. Regressions though coherent populations of plagioclase microcrysts, for which assumptions of near-uniform morphologies are valid, are shown as thick solid lines. Data shown with white crosses are excluded from these regressions either because they lie below the spatial resolution of measurements or because they overlap populations of larger plagioclase macrocrysts. Complete CSDs are illustrated with thin dashed lines, and are repeated in a series of inset figures for clarity. 
grain sizes in which an abundance of groundmass plagioclase agglomerations biases calculations and results in concave-up CSDs. Therefore, CSDs from QEMSCAN images are most comparable with their manual counterparts at larger grain sizes $\left(A^{0.5}>0.2\right.$ $\mathrm{mm}$ ) where both automated segmentation and manual rectification processes are more reliable.

CSDs calculated from QEMSCAN images of porphyritic rocks are thus prone to greater uncertainties than those calculated from traced images because it is challenging to produce grain maps automatically. Nonetheless, even CSDs calculated from unrectified QEMSCAN images reproduce the samples' two most important textural features: the division of plagioclase crystals into microcryst and macrocryst populations, and the higher number density of macrocrysts in samples from episodes VII and VIII than in samples from episodes I and III. Although CSDs from labor-intensive, manually collected data sets are still required for accurate quantification, CSDs from automatically collected data sets can nevertheless provide a rapid overview of textural features with minimal user input.

\section{Surface transport}

Although the textural properties of volcanic rocks can be used to investigate deep magmatic processes (Higgins and Roberge 2007; Armienti et al. 2013; Fornaciai et al. 2015), it is also important to assess the effects of surface transport on the evolution of rock textures. This is especially important in the case of the Laki eruption because thermally efficient transport over long distances resulted in continued evolution of the lava during emplacement (Guilbaud et al. 2007). For example, combining the minimum rate of lava surge advance ( $2 \mathrm{~km}$ per day) with a maximum lava transport distance $(\sim 40 \mathrm{~km})$ indicates that some lava batches may have been transported within channels and lava tubes for at least 20 days before final emplacement (Thordarson and Self 1993). Indeed, surface transport timescales on the order of days are sup-
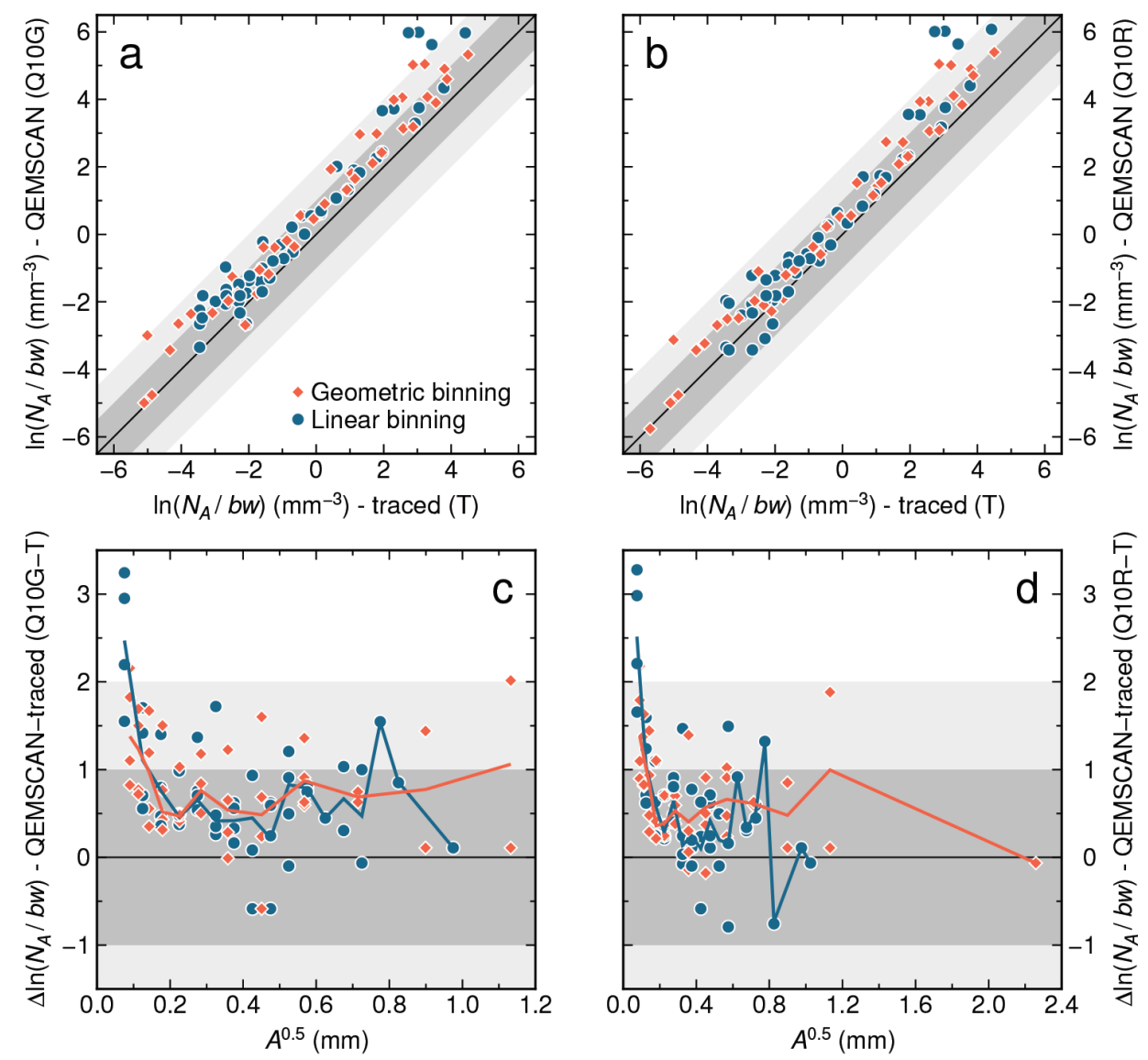

FIGURE 11. (a and b) Plots showing how $\ln \left(N_{A} / b w\right)$ determined from traced thin section images (T) compares with $\ln \left(N_{A} / b w\right)$ from (a) unrectified but granulated QEMSCAN (Q10G) and (b) rectified QEMSCAN images (Q10R) when binned linearly (blue) and geometrically (red). Values of $\ln \left(N_{A} / b w\right)$ are almost always higher in plagioclase size distributions calculated from QEMSCAN images. One and two log unit deviations from the one-to-one line are marked by the dark and light fields, respectively. (c and d) Plots showing how differences between $\ln \left(N_{A} / b w\right)$ determined from traced thin section images $(\mathrm{T})$ and QEMSCAN images $\left[\Delta \ln \left(N_{A} / b w\right)\right]$ vary as a function of plagioclase size for $\mathbf{c}$ unrectified but granulated QEMSCAN images $(\mathrm{Q} 10 \mathrm{G})$ and $(\mathbf{d})$ rectified QEMSCAN images (Q10R) when binned geometrically (red) and linearly (blue). Lines show running mean $\Delta \ln \left(N_{A} / b w\right)$ values calculated by passing Gaussian filters with $0.1 \mathrm{~mm}$ bandwidths across each data set. At plagioclase sizes of $A^{0.5}>0.2 \mathrm{~mm}, \ln \left(N_{A} / b w\right)$ values from QEMSCAN images are generally half a $\log$ unit higher than $\ln \left(N_{A} / b w\right)$ values from traced images. At $A^{0.5}<0.2 \mathrm{~mm}$, the overestimation of $\ln \left(N_{A} / b w\right)$ values increases toward a maximum of three log units. 
ported by timescales of diffusive $\mathrm{H}_{2} \mathrm{O}$ loss from olivine-hosted melt inclusions collected from lava selvages 5-30 km downstream from the eruption site $(4.0 \pm 3.4(1 \sigma)$ days; Hartley et al. 2015).

Samples were collected at different distances from their source vents (Fig. 1), implying that they experienced different posteruptive thermal histories. Although plagioclase contents roughly correlate with transport distances (LAK09, which was collected at $<1 \mathrm{~km}$ from its source vent, has the lowest crystal content, whereas LAK27, which was collected at $\sim 40 \mathrm{~km}$, has the highest), most microcrysts are still too large to have grown during emplacement and must reflect earlier magmatic processes. However, a mixture of pre- and post-eruptive processes could be recorded in the size distributions of the plagioclase microcrysts $(L=0.15-0.50 \mathrm{~mm})$.

For stereologically corrected CSDs (Fig. 10), gradients of fits through plagioclase microcryst populations $(-1 / G \tau)$ become shallower with increasing distance from the samples' source vents: $-12.2 \mathrm{~mm}^{-1}$ in LAK09 $(<1 \mathrm{~km}) ;-11.1 \mathrm{~mm}^{-1}$ in LAK18 $(\sim 5$ $\mathrm{km}) ;-9.5 \mathrm{~mm}^{-1}$ in LAK04 $(\sim 15 \mathrm{~km})$; and $-8.4 \mathrm{~mm}^{-1}$ in LAK27 ( $\sim 40 \mathrm{~km})$. Assuming that all samples contained similar microcryst populations at the time of eruption, as implied by the compositional homogeneity of microcrysts ejected throughout the course of the eruption (Guilbaud et al. 2007; Neave et al. 2013), these textural differences are best accounted for by varying degrees of CSD ripening during surface transport (Cashman and Marsh 1988; Higgins and Roberge 2003): LAK04 and LAK27 were transported further prior to final emplacement than LAK18 and LAK09, and thus experienced a greater degree of post-eruptive textural modification.

\section{Mush disaggregation}

The relatively albitic composition of plagioclase microcrysts $\left(\sim \mathrm{An}_{70} ; L<0.5 \mathrm{~mm}\right)$ reflects their growth from liquids closely associated with erupted tephra glasses (Guilbaud et al. 2007; Neave et al. 2013). In contrast, macrocrysts $(L>0.5 \mathrm{~mm})$ are dominantly composed of high-anorthite cores $\left(\mathrm{An}_{84}-\mathrm{An}_{92} ;\right.$ Fig. 8) that are far from being in equilibrium with tephra glasses. Indeed, these high-anorthite compositions cannot be related to the erupted glasses by evolution along a simple single liquid line of descent (Neave et al. 2013): no melts with sufficiently high $\mathrm{Ca} / \mathrm{Na}$ values to stabilize high-anorthite plagioclase can be generated by adding observed phase compositions back into the magmatic tephra compositions. By combining these findings with records of trace element heterogeneity in olivine-hosted melt inclusions associated with high-anorthite plagioclase cores, Neave et al. (2013) suggested that primitive macrocrysts were sourced from disaggregated crystal mushes formed from a distribution of mantle melts different from that which formed the erupted liquid. The CSDs and size-composition information (Figs. 8-10) presented here provide strong independent evidence for the pre-eruptive entrainment of disequilibrium macrocrysts into the Laki carrier liquid.

Although episodes I-V were the most vigorous and productive of the Laki eruption (Thordarson and Self 1993), lavas from these episodes contain the fewest crystals ( $<9 \%$ by area; Fig. $14 \mathrm{~b}$ in Passmore et al. 2012). In contrast, lavas from fissures VII-VIII carry considerable crystal loads (mean $19 \%$ by area; Fig. $14 b$ in Passmore et al. 2012). Fits through macrocryst populations in CSDs from LAK04 and LAK27 (fissures VII and VIII) have shallower gradients and higher intercept values than similar fits through macrocryst populations in LAK18 and LAK09 (fissures I and III) (Figs. 9 and 10), implying that macrocrysts are not only larger in the products of these later episodes, but that they are also more abundant. Thus, given that only modest differences between microcryst populations from different samples can be attributed to post-eruptive processes, the total crystal content of lava samples reflects primarily the abundance of macrocrysts and hence the amount of mush entrainment at depth.

When combined with the full point-counting data set of Passmore et al. (2012), our CSDs suggest that the efficiency of mush disaggregation and consequent macrocryst entrainment increased significantly between episodes I-III and episodes VII-VIII. A lower macrocryst content in episodes IX and $\mathrm{X}$ also suggests that macrocryst entrainment efficiency may have decreased toward the end of the eruption (Passmore et al. 2012). While variability in disaggregation efficiency may represent lateral variations in mush and cumulate petrology at depth, dynamic processes may have also been important. However, evaluating the controls on mush disaggregation efficiency is beyond the scope of this study, and may be approached better using numerical approaches (e.g., Bergantz et al. 2015; Schleicher et al. 2016).

\section{Timescales of mush disaggregation}

Plagioclase microcrysts record the final phase of crystallization before eruption that, according to crystal zoning patterns, must have occurred immediately after the entrainment of large, primitive macrocrysts. Stereologically corrected CSDs of plagioclase microcrysts thus record information about how timescales between disaggregation and ejection at the surface evolved as the eruption proceeded.

Once uncertainties in stereological conversions and the identification of coherent crystal populations have been minimized, crystal growth rates represent the largest source of error when estimating crystallization times from CSDs (Fornaciai et al. 2015). Plagioclase growth rates estimated from recent isobaric and isothermal crystallization experiments on mafic compositions are within the range $G$ $=10^{-8}-10^{-5} \mathrm{~mm} / \mathrm{s}$ (Conte et al. 2006; Orlando et al. 2008; Agostini et al. 2013; Shea and Hammer 2013), with experiments carried out on an anhydrous trachybasalt from Etna at low degrees of undercooling probably representing the most relevant growth rates for the Laki system $\left(G \sim 0.5 \times 10^{-7} \mathrm{~mm} / \mathrm{s}\right.$; Orlando et al. 2008). These growth rates are also broadly consistent with experiments carried out on a hydrous high-K basalt from Stromboli at low degrees of undercooling ( $G \sim 10^{-7}-10^{-6} \mathrm{~mm} / \mathrm{s}$; Agostini et al. 2013). Thus, assuming $0.5-5 \times 10^{-7} \mathrm{~mm} / \mathrm{s}$ as a range of feasible growth rates, we estimate that plagioclase microcrysts in LAK18 and LAK09 crystallized over 2-20 days. Equivalent crystals in LAK04 and LAK27 record timescales of 2.4-24 and 2.8-28 days, respectively. Differences in timescales between proximal (LAK18 and LAK09) and distal (LAK04 and LAK27) samples of up 0.4-8 days are however consistent with the degree textural of ripening expected to occur in the distal samples as a result of surface transport (see above). Thus, once the effects of post-eruptive modification have been accounted for, plagioclase microcrysts in all samples record coherent crystallization timescales of $\sim 2-20$ days, regardless of their position in the eruption's chronology.

Plagioclase microcryst crystallization timescales are equivalent to the timescales of rim formation on primitive macrocrysts and 
thus constrain their entrainment timescales (Neave et al. 2013). It is therefore encouraging that our 2-20 days residence timescale for primitive macrocrysts in the Laki carrier liquid brackets the 6-10 days timescale estimated by modeling the diffusive re-equilibration of olivine macrocryst rims from episodes I, III, and V (Hartley et al. 2016). Further validation of our 2-20 days disaggregation timescale estimate, and hence our choice of plagioclase growth rates, is provided by the elevated water content of primitive olivinehosted inclusions in magmatic tephra samples: the extent of diffusive over-hydration observed in these inclusions requires that entrained macrocrysts spent a minimum of 2.5-19.1 days in the evolved Laki carrier liquid prior to eruption (Hartley et al. 2015). Moreover, the high mean aspect ratios of plagioclase microcrysts (length/width > 4) are indicative of crystallization timescales in the order of days to tens of days, whereas the low mean aspect ratios (length/width $=2-3$ ) of large plagioclase macrocrysts are consistent with much longer crystallization timescales of years to hundreds of years, assuming that crystallization was continuous (Holness 2014). As noted by Hartley et al. (2016), a 2-20 days timescale is not only much shorter than the total duration of the eruption (245 days), but is also comparable in length with the intervals between eruptive episodes (1-28 days; Thordarson and Self 1993).

\section{IMPLICATIONS}

When compared with manual point-counting approaches, automated approaches can greatly overestimate the erupted crystal content of porphyritic samples unless phase identification algorithms are specifically tuned to take account of compositional differences between macrocrysts, microcrysts, and groundmass grains. Differences between CSDs generated by manual and automated techniques reflect the inefficient segmentation of glomerocrysts when processing QEMSCAN images, and thus highlight the limited utility of this technique for studying syneruptive processes recorded by the smallest of crystals. However, CSDs derived from automatically generated images do recapitulate the main features of CSDs from manually traced images, meaning that magma reservoir processes recorded by larger macrocrysts are suitable for investigation with automated mineralogical methods. Many textural properties of volcanic rocks can thus be estimated with a fraction of the user input required for traditional methods. For example, key samples suitable for high-resolution but labor-intensive manual analysis can be selected from larger samples suites by performing automated analyses beforehand: while generating CSDs from thin section images can take tens of hours, generating CSDs from QEMSCAN data sets takes a matter of minutes (though collecting high-resolution QEMSCAN images still requires several hours of instrument time).

Large $(L>0.5 \mathrm{~mm})$, low aspect ratio (length/width $=2-3)$ macrocrysts from the Laki lava flow contain uniformly primitive cores $\left(\mathrm{An}_{84}-\mathrm{An}_{92}\right)$, whereas small $(L<0.5 \mathrm{~mm})$, high aspect ratio (length/width $>4)$ microcrysts are always more evolved $\left(<\mathrm{An}_{80}\right)$ and approach compositions in equilibrium with the erupted melt $\left(\sim \mathrm{An}_{65}\right)$. Large plagioclase macrocryst cores are too anorthitic to be related to the erupted melt by simple fractional crystallization and were probably sourced from disaggregating crystal mushes. Variations in macrocryst contents and CSDs between samples demonstrate that macrocryst entrainment efficiency varied during the course of the eruption: samples from later eruptive episodes (VII and VIII) carry a greater mush-derived component than samples from early episodes (I and III).

Compositional zoning patterns indicate that microcrysts grew immediately after the entrainment of macrocrysts and can therefore be used to constrain timescales between mush disaggregation and eruption. In turn, these timescales can be used to test whether mush disaggregation occurred in a single event before the eruption started (Scenario 1 in Fig. 12), or throughout the course of the eruption (Scenario 2 in Fig. 12). Using geologically plausible plagioclase growth rates, we estimate 2-20 days timescales for the simultaneous growth of microcrysts and entrainment of macrocrysts that are in good agreement with estimates from independent geochronometers. These timescales are also comparable with inter-episode repose times, implying that primitive macrocrysts erupted in later episodes were locked within mushes when the eruption started. We therefore conclude that mush disaggregation occurred throughout the course of the eruption (Scenario 2 in Fig. 12), with magmas from each episode being assembled on the order of 10 days before being ejected from their respective source vents. Importantly, an approximately 10-day time frame corresponds with historical records of seismicity before the onset of many eruptive episodes (Fig. 12; Thordarson and Self 1993, and references therein). Pre-eruptive seismicity may have conceivably been generated by the same magma movements that resulted in mush disaggregation; petrological and geophysical expressions of magmatism appear to be related at Laki.

Our textural observations imply that the near-homogenous composition of the Laki magma cannot have formed during a single mixing event (Scenario 1 in Fig. 12). With the sole exception of mush entrainment efficiency, magma assembly and evolution processes must have thus remained remarkably consistent throughout the eruption because the products of different eruptive episodes have very similar compositions despite their separation in space and time (Passmore et al. 2012). That is, successive batches of erupted magma must have crystallized from similar parental magma distributions under similar $P$ - $T$ conditions, suggesting that there were no substantial changes in reservoir architecture over an eight-month period.

Our findings also suggest that the magma feeding the 15.1 $\mathrm{km}^{3}$ eruption was mobilized in a punctuated manner. Specifically, the short entrainment and mush disaggregation timescales we calculate imply that magma batches from each episode were only mobilized a matter of days before their eruption. Indeed, close temporal relationships between eruptions and ground deformation events during the 1977-1984 CE Krafla Fires in north Iceland demonstrate that repeated phases of magma movement and, conceivably, mush entrainment are unlikely to be unique to Laki (Björnsson 1985). Moreover, compositional heterogeneity in the products of the 1730-1736 CE Timanfaya eruption on Lanzarote and 871 and $1477 \mathrm{CE}$ Veiðivötn eruptions in Iceland confirm that fissure eruptions are often fed from plumbing systems in which communication between different magma batches is incomplete or completely absent (Carracedo et al. 1992; Sigmarsson et al. 1998; Zellmer et al. 2008).

One key implication of the progressive mobilization we infer here is that the volume of eruptible magma in the Laki plumbing system at any given time was probably much closer the $1-2 \mathrm{~km}^{3}$ erupted per episode than the final erupted volume of 


\section{Scenario 1: Single mush disaggregation event before the eruption started}

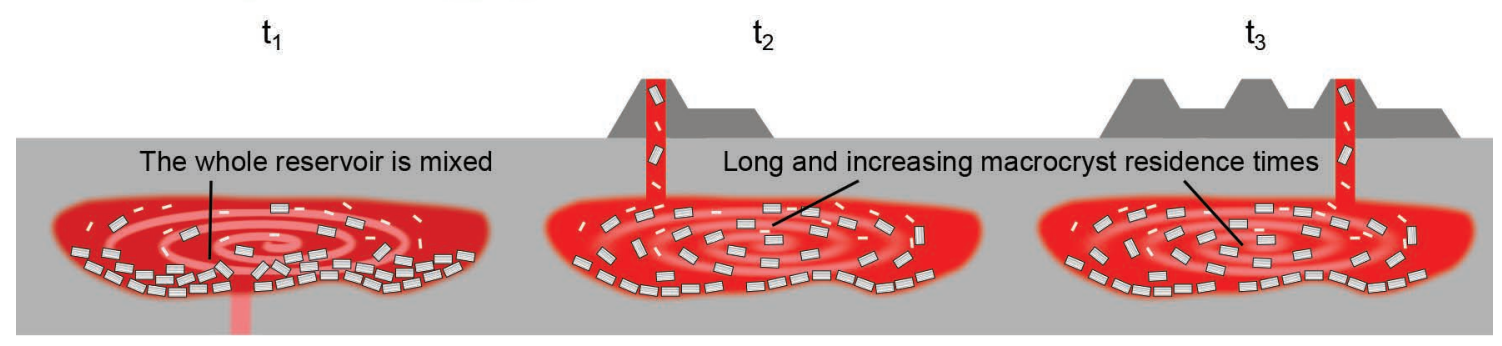

\section{Scenario 2: Continuous mush disaggregation throughout the eruption}

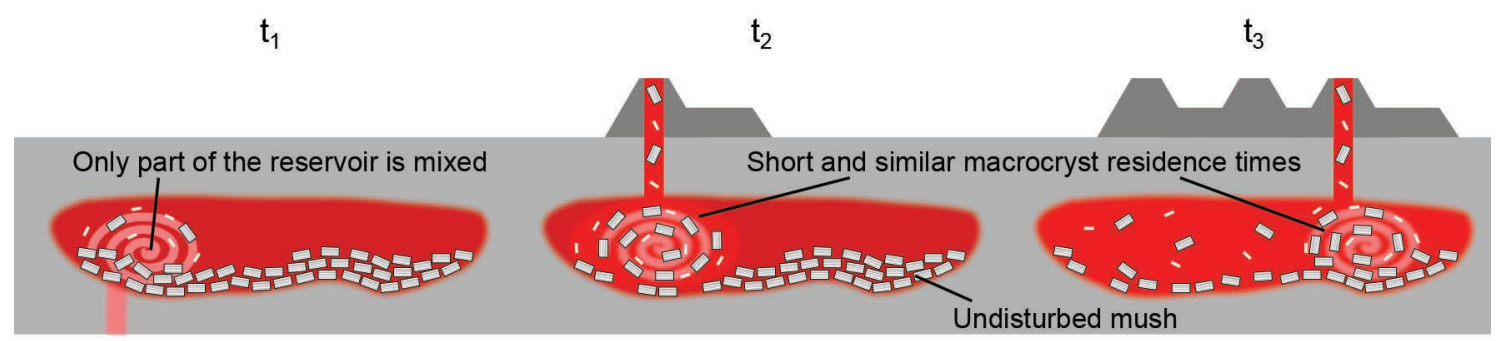

\section{Chronology of the Laki eruption}

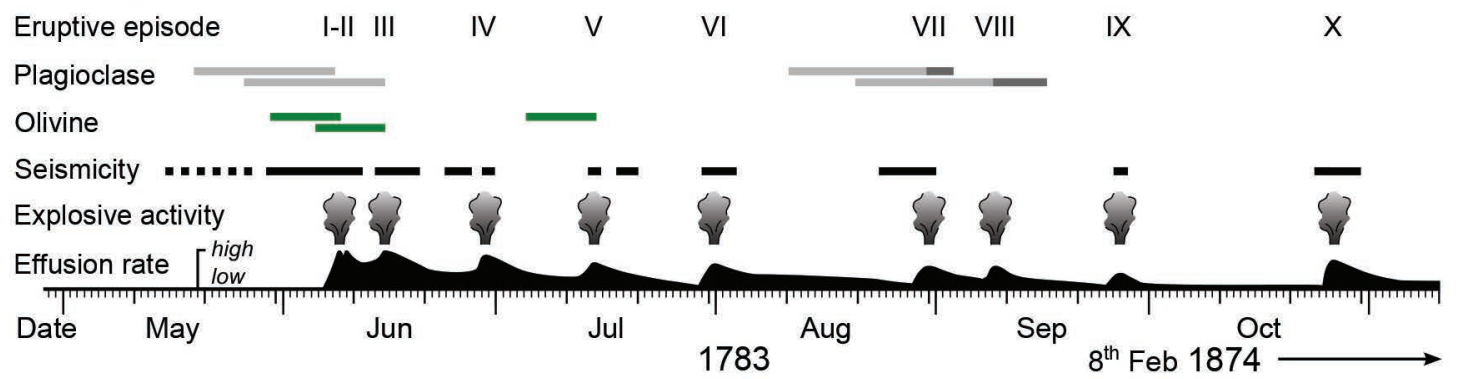

FIGURE 12. A cartoon summarizing two scenarios for mush disaggregation in the Laki magmatic system. Note that the lateral distribution of mush disaggregation is shown for illustrative purposes only. In Scenario 1, mush disaggregation and macrocryst entrainment occur in a single event before the onset of eruption such that macrocryst residence times from each episode increase as the eruption proceeds. In Scenario 2, mush disaggregation occurs throughout the eruption resulting in the progressive entrainment of new macrocryst batches such that macrocrysts from different episodes record short and similar residence times. Consistent growth timescales of 2-20 days estimated from plagioclase microcryst textures erupted from episodes I, III, VII, and VIII indicate that mush disaggregation and macrocryst entrainment took place throughout the Laki eruption, i.e., samples from the Laki eruption are consistent with Scenario 2. A schematic illustration of the Laki eruption's chronology, modified after Thordarson et al. (1996), is shown at the bottom of the figure. Maximum timescales of pre-eruptive mush disaggregation and macrocryst entrainment inferred from plagioclase CSDs (this study) and Fe-Mg zoning in olivine (Hartley et al. 2016) are shown as pale gray and green bars, respectively. Dark gray bars represent timescales of textural modification during surface transport experienced by plagioclase microcrysts in two samples. Periods of strong and weak seismicity are shown as solid and dashed black lines, respectively (Thordarson et al. 1996, and references therein). Explosive activity at the Laki fissure is denoted by the eruption cloud symbols. The effusion rate is shown qualitatively and is not to scale.

$15.1 \mathrm{~km}^{3}$. Therefore, each episode probably involved a volume of mobilized magma comparable to that which fed the $1.5 \mathrm{~km}^{3}$ 2014-2015 Bárðarbunga-Holuhraun eruption (Guðmundsson et al. 2016). Given that Laki's eruptive episodes were similar in size to numerous documented eruptions from Iceland and elsewhere, the eruption's exceptionalism in the recent geological record may thus hinge more on its tremendous vigor than on the ultimate volume of its products: during some episodes, the same volume of lava was emplaced within in a few weeks as was emplaced during the whole six-month duration of the 2014-2015 BárðarbungaHoluhraun eruption.

\section{ACKNOWLEDGMENTS}

This work was supported by NERC grants NER/S/A/2004/12727, NE/1528277/1, and NE/I012508/1. D.A.N. acknowledges support from the Alexander von Humboldt Foundation. We thank Margaret Hartley for her comments on an earlier draft of this manuscript and discussions on the Laki eruption, Simone Tommasini and one anonymous reviewer for their detailed and constructive comments, and Chiara Maria Petrone for her helpful guidance and efficient editorial handling.

\section{REFERENCES CITED}

Abràmoff, M.D., Magalhães, P.J., and Ram, S.J. (2004) Image processing with ImageJ. Biophotonics International, 11, 36-41.

Agostini, C., Fortunati, A., Arzilli, F., Landi, P., and Carroll, M.R. (2013) Kinetics of crystal evolution as a probe to magmatism at Stromboli (Aeolian Archipelago, Italy). Geochimica et Cosmochimica Acta, 110, 135-151. 
Albarède, F., and Tamagnan, V. (1988) Modelling the recent geochemical evolution of the Piton de la Fournaise volcano, Réunion Island 1931-1986. Journal of Petrology, 29, 997-1030.

Armienti, P. (2008) Decryption of igneous rock textures: Crystal size distribution tools. Reviews in Mineralogy and Geochemistry, 69, 623-649.

Armienti, P., Pareschi, M.T., Innocenti, F., and Pompilio, M. (1994) Effects of magma storage and ascent on the kinetics of crystal growth: The case of the 1991-93 Mt. Etna eruption. Contributions to Mineralogy and Petrology, 115, 402-414.

Armienti, P., Perinelli, C., and Putirka, K.D. (2013) A new model to estimate deeplevel magma ascent rates, with applications to Mt. Etna (Sicily, Italy). Journal of Petrology, 54, 795-813.

Bergantz, G.W., Schleicher, J.M., and Burgisser, A. (2015) Open-system dynamics and mixing in magma mushes. Nature Geoscience, 8, 793-796.

Björnsson, A. (1985) Dynamics of crustal rifting in NE Iceland. Journal of Geophysical Research, 90, 10,151-10,162.

Carracedo, J.C., Rodriguez Badiola, E., and Soler, V. (1992) The 1730-1736 eruption of Lanzarote, Canary Islands: a long, high-magnitude basaltic fissure eruption. Journal of Volcanology and Geothermal Research, 53, 239-250.

Cashman, K.V., and Marsh, B.D. (1988) Crystal size distribution (CSD) in rocks and the kinetics and dynamics of crystallization II: Makaopuhi lava lake. Contributions to Mineralogy and Petrology, 99, 292-305.

Conte, A.M., Perinelli, C., and Trigila, R. (2006) Cooling kinetics experiments on different Stromboli lavas: Effects on crystal morphologies and phases composition. Journal of Volcanology and Geothermal Research, 155, 179-200.

Cooper, K.M., Sims, K.W.W., Eiler, J.M., and Banerjee, N. (2016) Timescales of storage and recycling of crystal mush at Krafla Volcano, Iceland. Contributions to Mineralogy and Petrology, 171, 54.

Cordier, P., Demouchy, S., Beausir, B., Taupin, V., Barou, F., and Fressengeas, C. (2014) Disclinations provide the missing mechanism for deforming olivine-rich rocks in the mantle. Nature, 507, 51-56.

Donaldson, C.H., and Brown, R.W. (1977) Refractory megacrysts and magnesium-rich melt inclusions within spinel in oceanic tholeiites: Indicators of magma mixing and parental magma composition. Earth and Planetary Science Letters, 37, 81-89.

Fornaciai, A., Perinelli, C., Armienti, P., and Favalli, M. (2015) Crystal size distributions of plagioclase in lavas from the July-August 2001 Mount Etna eruption. Bulletin of Volcanology, 77, 70 .

Gottlieb, P., Wilkie, G., Sutherland, D., Ho-Tun, E., Suthers, S., Perera, K., Jenkins, B., Spencer, S., Butcher, A.R., and Rayner, J. (2000) Using quantitative electron microscopy for process mineralogy applications. Jom, 52, 24-25.

Guðmundsson, M.T., Jónsdóttir, K., Hooper, A., Holohan, E.P., Halldórsson, S.A., Ófeigsson, B.G., Cesca, S., Vogfjörd, K.S., Sigmundsson, F., Högnadóttir, T., and others. (2016) Gradual caldera collapse at Bárdarbunga volcano, Iceland, regulated by lateral magma outflow. Science, 353, aaf8988.

Guilbaud, M.-N., Blake, S., Thordarson, T., and Self, S. (2007) Role of Syn-eruptive Cooling and Degassing on Textures of Lavas from the AD 1783-1784 Laki Eruption, South Iceland. Journal of Petrology, 48, 1265-1294.

Halldórsson, S.A., Óskarsson, N., Sigurdsson, G., Sverrisdottir, G., and Steinthórsson, S. (2008) Isotopic-heterogeneity of the Thjorsa lava-Implications for mantle sources and crustal processes within the Eastern Rift Zone, Iceland. Chemical Geology, 255, 305-316.

Hansen, H., and Grönvold, K. (2000) Plagioclase ultraphyric basalts in Iceland: The mush of the rift. Journal of Volcanology and Geothermal Research, 98, 1-32.

Hartley, M.E., Neave, D.A., Maclennan, J., Edmonds, M., and Thordarson, T. (2015) Diffusive over-hydration of olivine-hosted melt inclusions. Earth and Planetary Science Letters, 425, 168-178

Hartley, M.E., Morgan, D.J., Maclennan, J., Edmonds, M., and Thordarson, T. (2016) Tracking timescales of short-term precursors to large basaltic fissure eruptions through Fe-Mg diffusion in olivine. Earth and Planetary Science Letters, 439, 58-70.

Higgins, M.D. (1996) Magma dynamics beneath Kameni volcano, Thera, Greece, as revealed by crystal size and shape measurements. Journal of Volcanology and Geothermal Research, 70, 37-48.

(2000) Measurement of crystal size distributions. American Mineralogist, 85, $1105-1116$.

(2006) Quantitative Textural Measurements in Igneous and Metamorphic Petrology, 276 p. Cambridge University Press, U.K.

Higgins, M.D., and Roberge, J. (2003) Crystal size distribution of plagioclase and amphibole from Soufriere Hills Volcano, Montserrat: Evidence for dynamic crystallization-textural coarsening cycles. Journal of Petrology, 44, 1401-1411.

(2007) Three magmatic components in the 1973 eruption of Eldfell volcano, Iceland: Evidence from plagioclase crystal size distribution (CSD) and geochemistry. Journal of Volcanology and Geothermal Research, 161, 247-260.

Holness, M.B. (2014) The effect of crystallization time on plagioclase grain shape. Contributions to Mineralogy and Petrology, 168, 1076.

Holness, M.B., Anderson, A.T., Martin, V.M., Maclennan, J., Passmore, E., and Schwindinger, K.R. (2007) Textures in partially solidified crystalline nodules: A window into the pore structure of slowly cooled mafic intrusions. Journal of Petrology, 48, 1243-1264.

Lange, A.E., Nielsen, R.L., Tepley, F.J., and Kent, A.J.R. (2013a) The petrogenesis of plagioclase-phyric basalts at mid-ocean ridges. Geochemistry, Geophysics, Geosystems, 14, 3282-3296. (2013b) Diverse Sr isotope signatures preserved in mid-oceanic-ridge basalt plagioclase. Geology, 41, 279-282.

Lofgren, G.E. (1974) An experimental study of plagioclase crystal morphology; isothermal crystallization. American Journal of Science, 274, 243-273.

Marsh, B.D. (1988) Crystal Size Distribution (CSD) in rocks and kinetics and dynamics of crystallization. I. Theory. Contributions to Mineralogy and Petrology, 99, 277-291.

(1998) On the interpretation of crystal size distributions in magmatic systems. Journal of Petrology, 39, 553-599.

Morgan, D.J., and Jerram, D.A. (2006) On estimating crystal shape for crystal size distribution analysis. Journal of Volcanology and Geothermal Research, 154, 1-7.

Neave, D.A., Passmore, E., Maclennan, J., Fitton, J.G., and Thordarson, T. (2013) Crystal-melt relationships and the record of deep mixing and crystallization in the AD 1783 Laki eruption, Iceland. Journal of Petrology, 54, 1661-1690.

Neave, D.A., Maclennan, J., Hartley, M.E., Edmonds, M., and Thordarson, T. (2014) Crystal storage and transfer in basaltic systems: the Skuggafjöll eruption, Iceland. Journal of Petrology, 55, 2311-2346.

Orlando, A., D’Orazio, M., Armienti, P., and Borrini, D. (2008) Experimental determination of plagioclase and clinopyroxene crystal growth rates in an anhydrous trachybasalt from Mt Etna (Italy). European Journal of Mineralogy, 20, 653-664.

Passmore, E., Maclennan, J., Fitton, J.G., and Thordarson, T. (2012) Mush disaggregation in basaltic magma chambers: Evidence from the AD 1783 Laki eruption. Journal of Petrology, 53, 2593-2623.

Pirrie, D., Butcher, A.R., Power, M.R., Gottlieb, P., and Miller, G.L. (2004) Rapid quantitative mineral and phase analysis using automated scanning electron microscopy (QemSCAN); potential applications in forensic geoscience. Geological Society, London, Special Publications, 232, 123-136.

Prior, D.J., Boyle, A.P., Brenker, F., Cheadle, M.C., Austin, D., Lopez, G., Peruzzo, L., Potts, G.J., Reddy, S., Spiess, R., and others. (1999) The application of electron backscatter diffraction and orientation contrast imaging in the SEM to textural problems in rocks. American Mineralogist, 84, 1741-1759.

Rhodes, J.M., Dungan, M.A., Blanchard, D.P., and Long, P.E. (1979) Magma mixing at mid-ocean ridges: Evidence from basalts drilled near $22^{\circ} \mathrm{N}$ on the Mid-Atlantic Ridge. Tectonophysics, 55, 35-61.

Ridley, I.W., Perfit, M.R., Smith, M.C., and Fornari, D.J. (2006) Magmatic processes in developing oceanic crust revealed in a cumulate xenolith collected at the East Pacific Rise, $9^{\circ} 50^{\prime} \mathrm{N}$. Geochemistry, Geophysics, Geosystems, 7, 1-25.

Sahagian, D.L., and Proussevitch, A.A. (1998) 3D particle size distributions from 2D observations: Stereology for natural applications. Journal of Volcanology and Geothermal Research, 84, 173-196.

Salaün, A., Villemant, B., Semet, M.P., and Staudacher, T. (2010) Cannibalism of olivine-rich cumulate xenoliths during the 1998 eruption of Piton de la Fournaise (La Réunion hotspot): Implications for the generation of magma diversity. Journal of Volcanology and Geothermal Research, 198, 187-204.

Schleicher, J.M., Bergantz, G.W., Breidenthal, R.E., and Burgisser, A. (2016) Time scales of crystal mixing in magma mushes. Geophysical Research Letters, 43, 1-8.

Shea, T., and Hammer, J.E. (2013) Kinetics of cooling- and decompression-induced crystallization in hydrous mafic-intermediate magmas. Journal of Volcanology and Geothermal Research, 260, 127-145.

Shea, T., Houghton, B.F., Gurioli, L., Cashman, K.V., Hammer, J.E., and Hobden, B.J. (2010) Textural studies of vesicles in volcanic rocks: An integrated methodology. Journal of Volcanology and Geothermal Research, 190, 271-289.

Sigmarsson, O., Condomines, M., Grönvold, K., and Thordarson, T. (1991) Extreme magma homogeneity in the 1783-84 Lakagigar Eruption: Origin of a large volume of evolved basalt in Iceland. Geophysical Research Letters, 18, 2229-2232.

Sigmarsson, O., Carn, S.A., and Carracedo, J.C. (1998) Systematics of U-series nuclides in primitive lavas from the 1730-36 eruption on Lanzarote, Canary Islands, and implications for the role of garnet pyroxenites during oceanic basalt formations. Earth and Planetary Science Letters, 162, 137-151.

Thomson, A., and Maclennan, J. (2013) The distribution of olivine compositions in Icelandic basalts and picrites. Journal of Petrology, 54, 745-768.

Thordarson, T., and Self, S. (1993) The Laki (Skaftár Fires) and Grímsvötn eruptions in 1783-1785. Bulletin of Volcanology, 55, 233-263.

Thordarson, T., Self, S., Óskarsson, N., and Hulsebosch, T. (1996) Sulfur, chlorine, and fluorine degassing and atmospheric loading by the 1783-1784 AD Laki (Skaftár Fires) eruption in Iceland. Bulletin of Volcanology, 58, 205-225.

Vinet, N., and Higgins, M.D. (2010) Magma solidification processes beneath Kilauea volcano, Hawaii: A quantitative textural and geochemical study of the 1969-1974 Mauna Ulu Lavas. Journal of Petrology, 51, 1297-1332.

Winpenny, B., and Maclennan, J. (2011) A partial record of mixing of mantle melts preserved in Icelandic phenocrysts. Journal of Petrology, 52, 1791-1812.

Zellmer, G.F., Rubin, K.H., Grönvold, K., and Jurado-Chichay, Z. (2008) On the recent bimodal magmatic processes and their rates in the Torfajokull-Veidivotn area, Iceland. Earth and Planetary Science Letters, 269, 387-397.

MANUSCRIPT RECEIVED NOVEMBER 14, 2016

MANUSCRIPT ACCEPTED JUNE 8, 2017

MANUSCRIPT HANDLED BY CHIARA MARIA PETRONE 